\title{
THE RELATIONSHIP BETWEEN BICYCLES AND TRAFFIC SAFETY FOR ALL ROAD USERS
}

\author{
A Thesis \\ presented to \\ the Faculty of California Polytechnic State University, \\ San Luis Obispo
}

\begin{abstract}
In Partial Fulfillment
of the Requirements for the Degrees

Master of City and Regional Planning

Master of Science in Engineering (Transportation Planning Specialization)

by
\end{abstract}

Jasmine A. Martin

December, 2014 
(C) 2014

Jasmine A. Martin

ALL RIGHTS RESERVED 


\section{COMMITTEE MEMBERSHIP}

TITLE:

The Relationship Between Bicycles and Traffic Safety for all Road Users

AUTHOR:

Jasmine A. Martin

DATE SUBMITTED:

December 10, 2014

COMMITTEE CHAIR:

Dr. Cornelius Nuworsoo,

Associate Professor of City \& Regional Planning

COMMITTEE MEMBER:

Dr. Anurag Pande

Associate Professor of Civil Engineering

COMMITTEE MEMBER:

Dr. William Riggs

Assistant Professor of City \& Regional Planning 


\begin{abstract}
The Relationship between Bicycles and Traffic Safety for All Road Users
\end{abstract}

Jasmine A. Martin

Over the past twenty years bicycle use as a mode of transportation has grown considerably in the United States. Other studies have examined the individual bicyclist's risk in proportion to the growth in cycling across cities, a phenomenon referred to as 'safety in numbers.' This study expands from that research and examines the effect of cyclists on road safety for all road users.

The study examines the roles of bicycle modal split, a city wide analysis, and bicycle infrastructure, a site based analysis, in road safety outcomes. For the city based analysis, twenty years of crash data in 12 California cities were analyzed over a 20 year period. This study primarily used census data and State wide Integrated Traffic Records System (SWITRS) data. This study concludes that as bicycle modal split increases in a city, the traffic fatalities tend to decrease and the relationship is an exponential function.

The site based analysis focuses on the effects of installing a bicycle lane on a street and examined its effect on injury crashes. 20 sites in San Francisco, CA that had bike lanes installed on them were compared to 25 control group sites, also in San Francisco, that did not have any bike lanes or other significant changes. An Empirical Bayes method of analysis was done to test its effects and determined that the effects were statistically significant.

Keywords: Safety, Bicycles, traffic fatalities 


\section{ACKNOWLEDGMENTS}

A special thanks to Andrew Stitt and Rachel Martin for their support, editing and cookie dough. A special thanks to Professors Cornelius Nuworsoo, Anurag Pande and William Wriggs for their time and support. 


\section{TABLE OF CONTENTS}

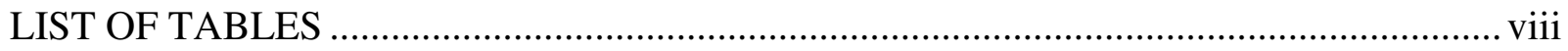

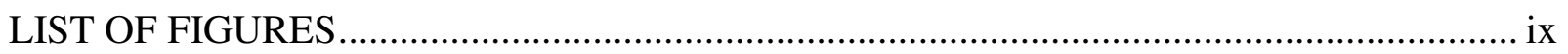

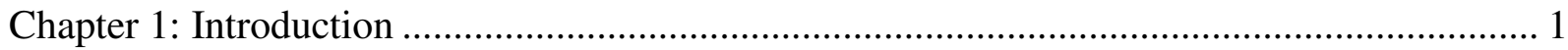

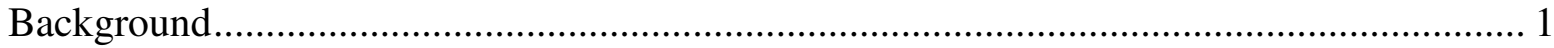

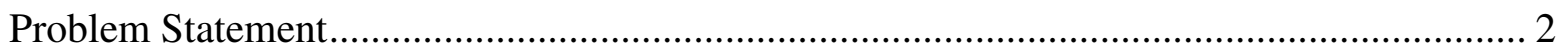

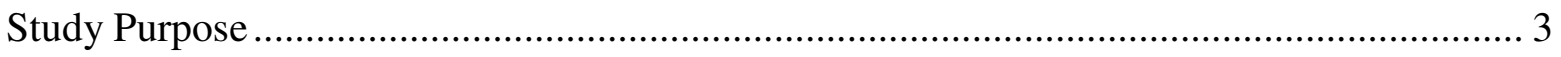

Relevance to Transportation Planning.............................................................................. 3

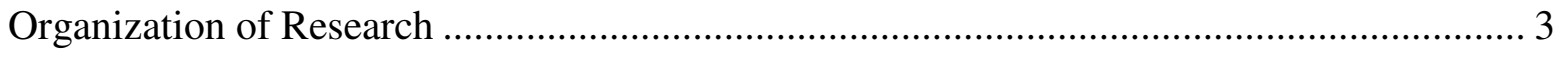

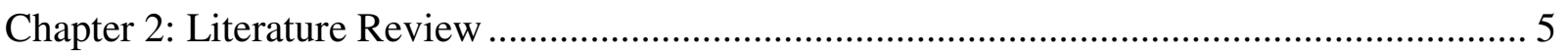

A Little Perspective: Traffic Fatalities in the United States and around the World................ 5

European cities compared to American Cities.................................................................. 7

New York City, a Changing Transportation System ........................................................ 10

Bike Friendly Cities and Safety: Davis....................................................................... 10

Build it and They Will Come.................................................................................... 12

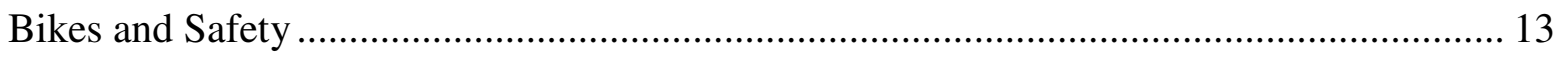

Bicycle Infrastructure and Bicycle Safety ................................................................. 14

The Relationship between Bicycle Infrastructure and Overall Safety ............................... 15

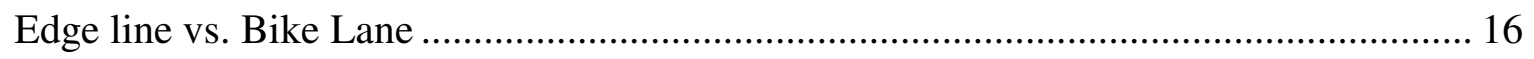

Safety in Numbers for Motorists and Smeed's Law .......................................................... 17

Motorist's Behavior and Fatalities................................................................................. 19

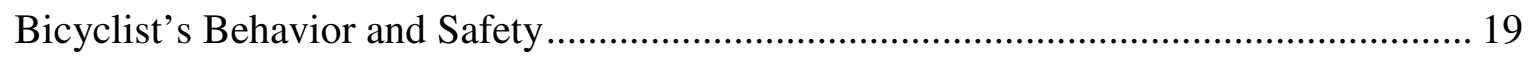

Safety and Inattention Blindness ............................................................................... 20

Driving in a Snow Storm, Risk Compensation and Risk Homeostasis ............................. 21

Bikes and their effect on Traffic Behavior .................................................................... 22

Bicycle Infrastructure as a Traffic Calming Measure..................................................... 23

Characteristics of Bicycle Friendly city that Contribute to Traffic Safety ........................ 23

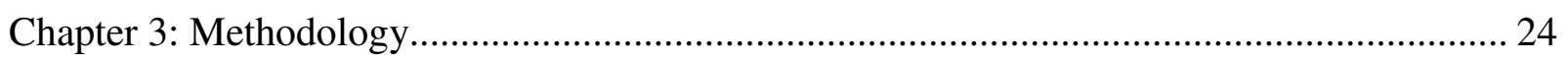

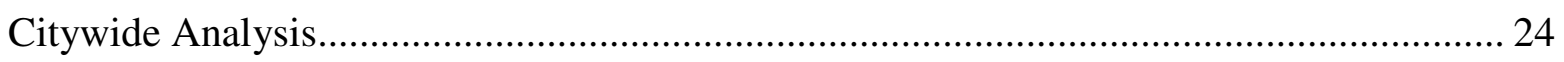

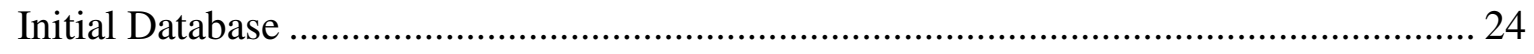

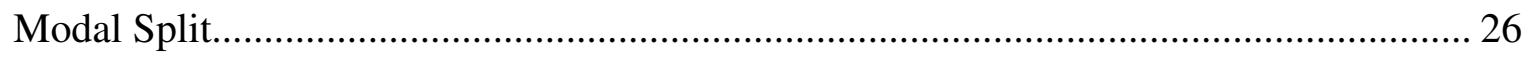




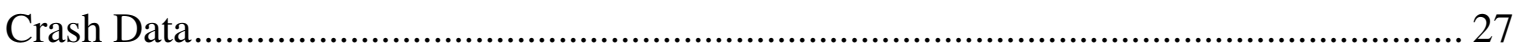

Statistical Analysis ................................................................................................ 28

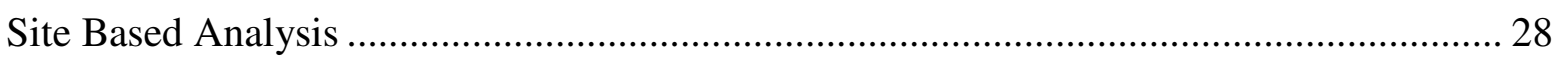

The Empirical Bayes Method using the Highway Safety Manual..................................... 29

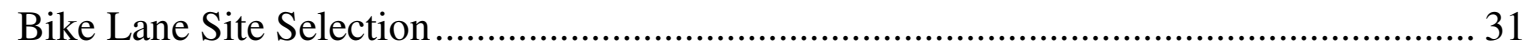

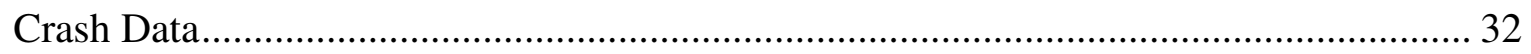

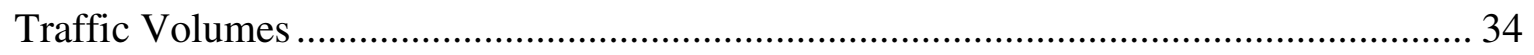

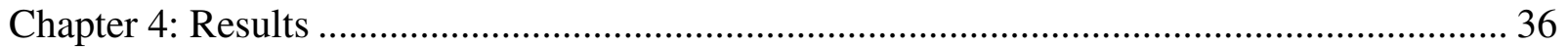

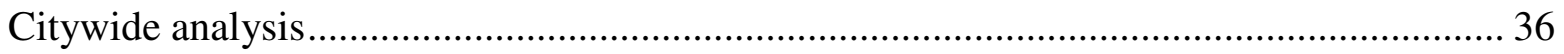

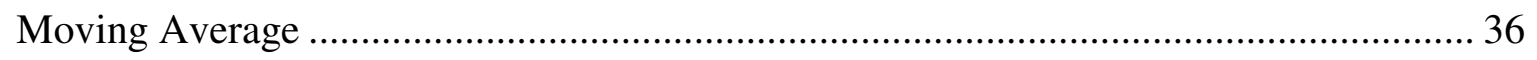

Curve estimation through Regression ........................................................................ 39

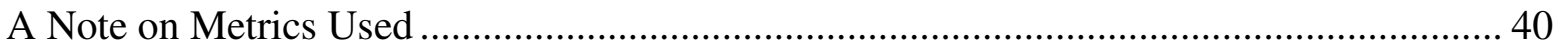

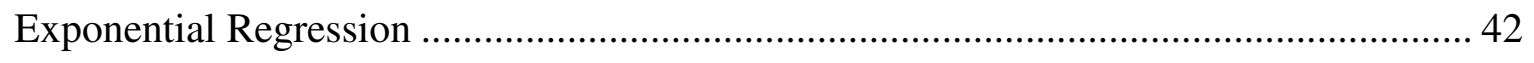

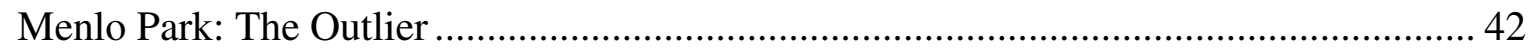

Non-Linear Regression .................................................................................... 43

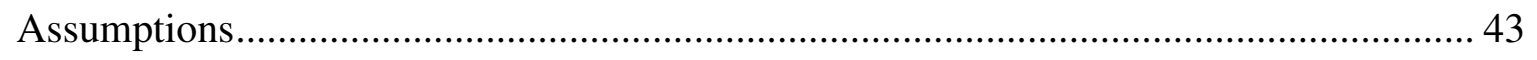

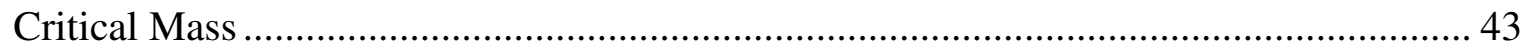

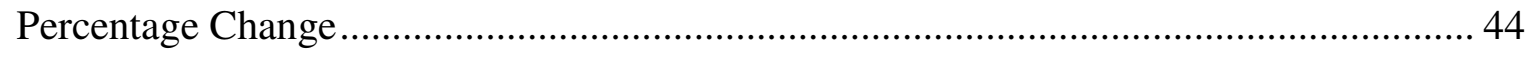

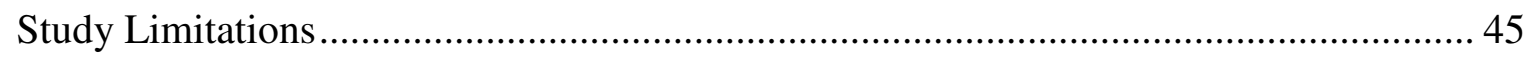

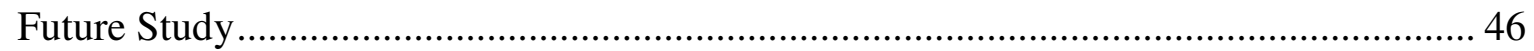

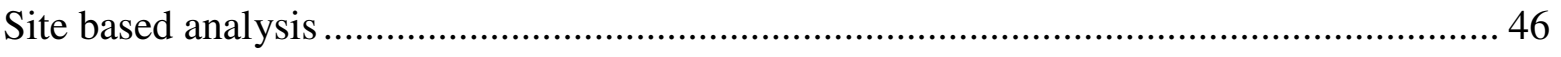

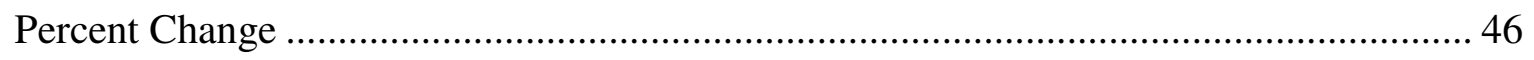

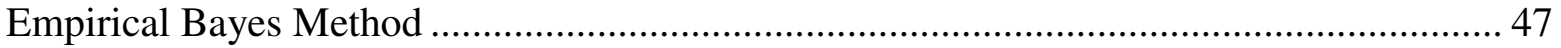

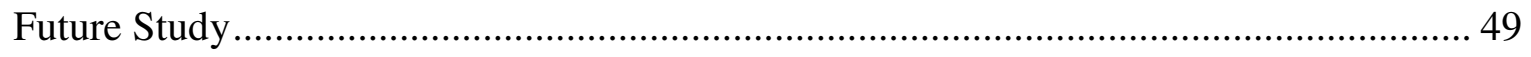

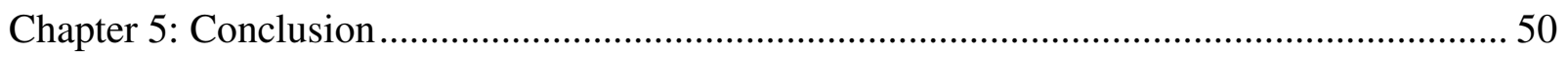

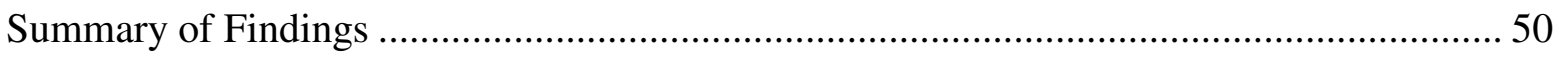

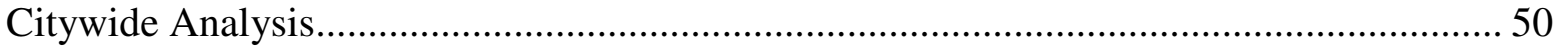

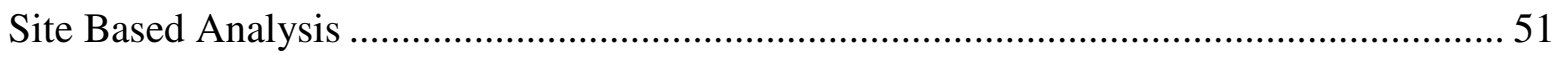

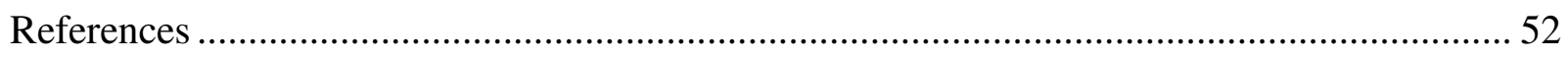

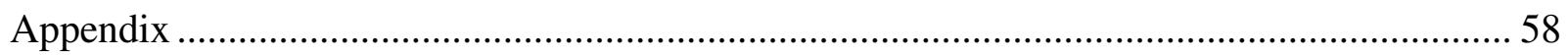




\section{LIST OF TABLES}

Table 1: 2000 and 2010 Mode Choice: State of California vs. Bike-Friendly Cities in the State 28

Table 2: Selected Sites for analysis ....

Table 3: Comparison of biking city's and California's average percent change of traffic fatality

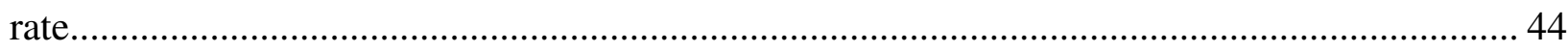

Table 4: Percent Change Comparison between Selected Sites and San Francisco Total ............ 47

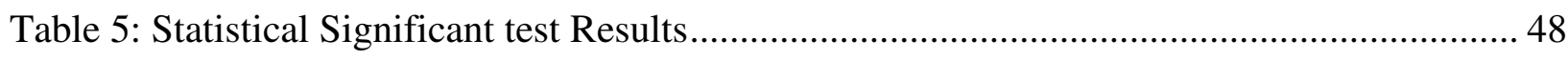




\section{LIST OF FIGURES}

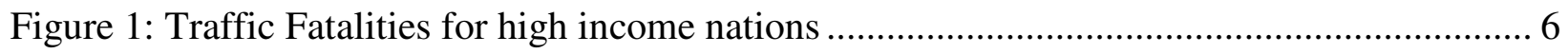

Figure 2: Traffic Fatalities for large U.S. Cities (New York City Pedestrian Action Plan, 2010) . 7

Figure 3: Portland Traffic Fatalities per population compared to US traffic Fatalities per

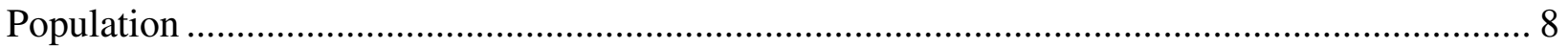

Figure 4: Traffic Fatalities in Portland compared to Pedestrian and Bike Traffic.......................... 9

Figure 5: Traffic Fatalities for California Cities with a population over 40,000 .......................... 11

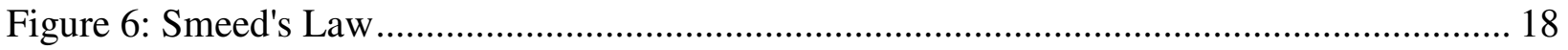

Figure 7: The percent of all fatal crashes by the percent of rural distance of vehicles traveled for

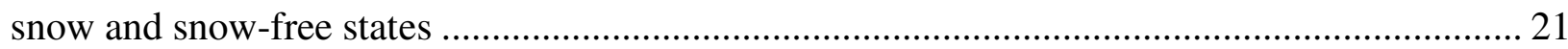

Figure 8: Bicycle Modal Split for Selected California Cities ................................................... 27

Figure 9: San Francisco Traffic crashes depicted as a heat map (TIMS, 2013) ........................... 33

Figure 10: Traffic Fatality rate for selected California Cities.................................................... 37

Figure 11: 10 year moving average for Selected California Cities.............................................. 38

Figure 12: Bicycle Modal Split vs. Traffic Fatalities for Selected California Cities..................... 39

Figure 13: Traffic Fatalities per population vs commuter cyclists per square mile...................... 42 


\section{Chapter 1: Introduction}

Background

Over the last decade, a growing number of urban planners and transportation professionals have come to the conclusion that bikes are in fact awesome (Mia Birk, (2010) Janette Sadik-Khan (2013), Mikael Colville-Andersen (2012), Dan Burden (2011)). Biking, specifically biking as a mode of transportation, have many benefits for cities. They improve air and water quality when used in place of motorized transportation, and they improve the health of their riders. Biking prevents and combats a number of common diseases such as obesity, depression, coronary heart disease, strokes, hypertension, colon cancer, breast cancer and type II diabetes. They offer cities a less expensive infrastructure as compared to vehicle infrastructure improvements, they improve the livability of cities and, as this research and others show, they also improve traffic safety. (Hendriksen et al., 2000; Carlos and Phillips, 2000; Wagner et al., 2001; Kjellstrom et al., 2003)

In recent years, bicycle ridership as a form of transportation has been on the rise. This new trend towards cycling is changing the shape of American cities. Thousands of miles of bike lanes have been added to city streets around the country in the last decade (Mapes, 2009). Bikes have been embraced as part of a solution to the growing concerns of climate change, high gas prices, livability, health concerns and congestion. These drastic changes have been met with growing enthusiasm but also mounting concerns, specifically when it comes to the topic of safety.

Safety is a topic of importance in any transportation context. Every type of transportation involves some inherent risk of harm, whether the form of transportation is a motor vehicle, biking, walking, or air travel. But safety is of particular significance when discussed in 
relationship to cycling. Safety concerns have been shown to be a major reason why people do not bike in American cities (Garrard et al., 2006; Goldsmith, 1992). "Cycling is viewed by many people who don't bike as being inherently dangerous" says Ed Barsotti from the League of Illinois Bicyclists (Mapes, 2009). Even people who do choose to cycle have an over exaggerated view of the risks, as one study that surveyed 300 cyclists in England shows (Burton, 2008).

The question, "Is it dangerous to bike", was posed to Peter Jacobsen, who had worked on the City of Pasadena Bicycle Plan. After some research he found that Pasadena had more bicycle crashes and fatalities than other cities, but Pasadena also had more bicyclists. This lead to a research paper that looked at 68 California cities, and concluded that "a motorist is less likely to collide with a person walking and bicycling if more people walk or bicycle" (Jacobsen, 2003). A non-linear relationship has been shown not only in California but also in Denmark, London, New York, Portland and the Netherlands (Transport for London, 2008; Jacobsen 2003; Robinson, 2005). A Netherlands traffic safety engineer calls this effect, "awareness in numbers." The theory behind 'awareness in numbers' is that as the number of cyclists increases the motorists adjust their behavior. Motorist behavior largely controls the likelihood of collisions with people walking and bicycling (Jacobsen, 2003). The observation that cyclists are changing motorists' behavior, which is in turn making cycling safer, also poses the question whether this change in behavior affects the safety of motorists.

\section{Problem Statement}

Cycling has been on the rise in American cities, changing the urban landscape, over the past 10 years. Despite this rise in cycling there is not much research on how this shift in modal split has affected whole transportation systems in American cities. While this change can affect 
many aspects of a city's transportation systems, this study specifically looks at how it affects safety, which is a concern for all modes of transportation.

\section{Study Purpose}

The purpose of this study is to determine if there is indeed a relationship between the emergence of bicycle usage and bicycle infrastructure in cities and the overall traffic fatalities of bicyclists, motorists and pedestrians. The study attempts to answer multiple questions: if there is a relationship, is it linear or nonlinear? Is there a measurable increase in traffic safety due to the presence of bicyclists or bicycle infrastructure? If there is a difference in safety at what point do bicyclists or bicycle infrastructure start affecting the city as a whole?

\section{Relevance to Transportation Planning}

Safety is a topic of importance in any field, but it is of particularly paramount importance in the field of transportation planning. Transportation safety is a field in which the United States in general has been lagging substantially behind its European counterparts for the last 20 years (World Health Organization, 2010). In that same time period Europe has been embracing biking and other modes of transportation to a much greater extent than the United States. Better understanding of the relationship between biking and overall traffic safety and specifically how it works in the United States can better inform decision makers who can use this knowledge to make the transportation system in United States cities safer for all road users.

\section{Organization of Research}

This study contains two complementary analyses to examine the safety effects of bicycles and bicycle related infrastructure. The first is a citywide analysis that looks at the effects of bicycle modal split at the citywide level. It involved the selection of 12 high bicycle modal split 
cities in California. The analysis then compared these cities' total traffic fatalities per population to their bicycle modal splits using a least square analysis to determine a relationship over twenty years of traffic fatality data.

The second is a site analysis that looks at the effects of the installation of class two bicycle infrastructure on injury and fatal crashes along street segments. Thirty-one sites were chosen from the City of San Francisco. Before and after period crashes were then compared to the City's traffic crash reduction as a whole. 
Chapter 2: Literature Review

A Little Perspective: Traffic Fatalities in the United States and around the World

"It's a dangerous business going out your door" (Tolkien, 1954). The mere act of leaving your front door and traveling from point A to point B is likely to be the most unsafe activity the average person does on a daily basis. 32,788 people died in transit in 2010 (National Highway Traffic Safety Administration, 2010). Traffic fatalities are the number one cause of death of people age 1-34 in the United States (National Highway Traffic Safety Administration, 2010). It also kills more than a million people worldwide every year, a number that is growing (World Health Organization, 2010) and, as Tom Vanderbilt describes it, 'if you drive an average of 15,500 miles a year, as many Americans do, there is a roughly 1 in 100 chance you'll die in a fatal car crash over a life time of 50 years of driving." (Vanderbilt, 2009, p.249)

Safety is therefore not a matter taken lightly by those in the transportation field, but it seems that it has not been emphasized in the United States as much as it has been in the rest of the world. While the United States has been doing a plethora of things to improve the safety of transportation such as better cars, air bags, seat belts, improved highway design, and law enforcement, the United States still lags behind the rest of the high-income countries in the world by a large margin. As shown in figure 1, according to the World Health Organization in 2010, the United States had a traffic fatality rate of 12.3 fatalities per 100,000 population per year (FHPY). While the United Kingdom had 3.59 FHPY, Japan had 3.85 FHPY, Germany had 4.5 FHPY, China had 5.1 FHPY, Australia had 5.7 FHPY and Canada had 9.2 FHPY. This lag is not only for just one year, but as a trend the gap has been increasing for the last 3 decades. From 1979 to 2002 Canada saw a decrease of fatalities of $49.9 \%$. The Great Britain saw a decrease of 
46.0\% and Australia decreased by $51.1 \%$. In the same time period America saw a decrease of only $16.2 \%$, well behind its foreign counterparts.

\section{Traffic Fatalities Rate in High Income Countries}

United

States

12.3
Canada
9.2
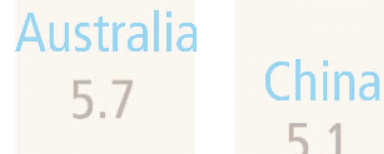

Germany

4.5

\section{Fatalities per 100,00 \\ inhabitants per year}

Data source: World Health Organization, 2010

Figure 1: Traffic Fatalities for high income nations 
European cities compared to American Cities

While much of the U.S. as a whole has much higher traffic fatality rates per population compared to other foreign countries of a similar GDP, a closer look at individual cities tells a similar story, but sheds light on the matter. Looking at individual cities, many large United States cities are still lagging behind their foreign counterparts, but some cities are doing much better

\section{Traffic Fatalities in Perspective}

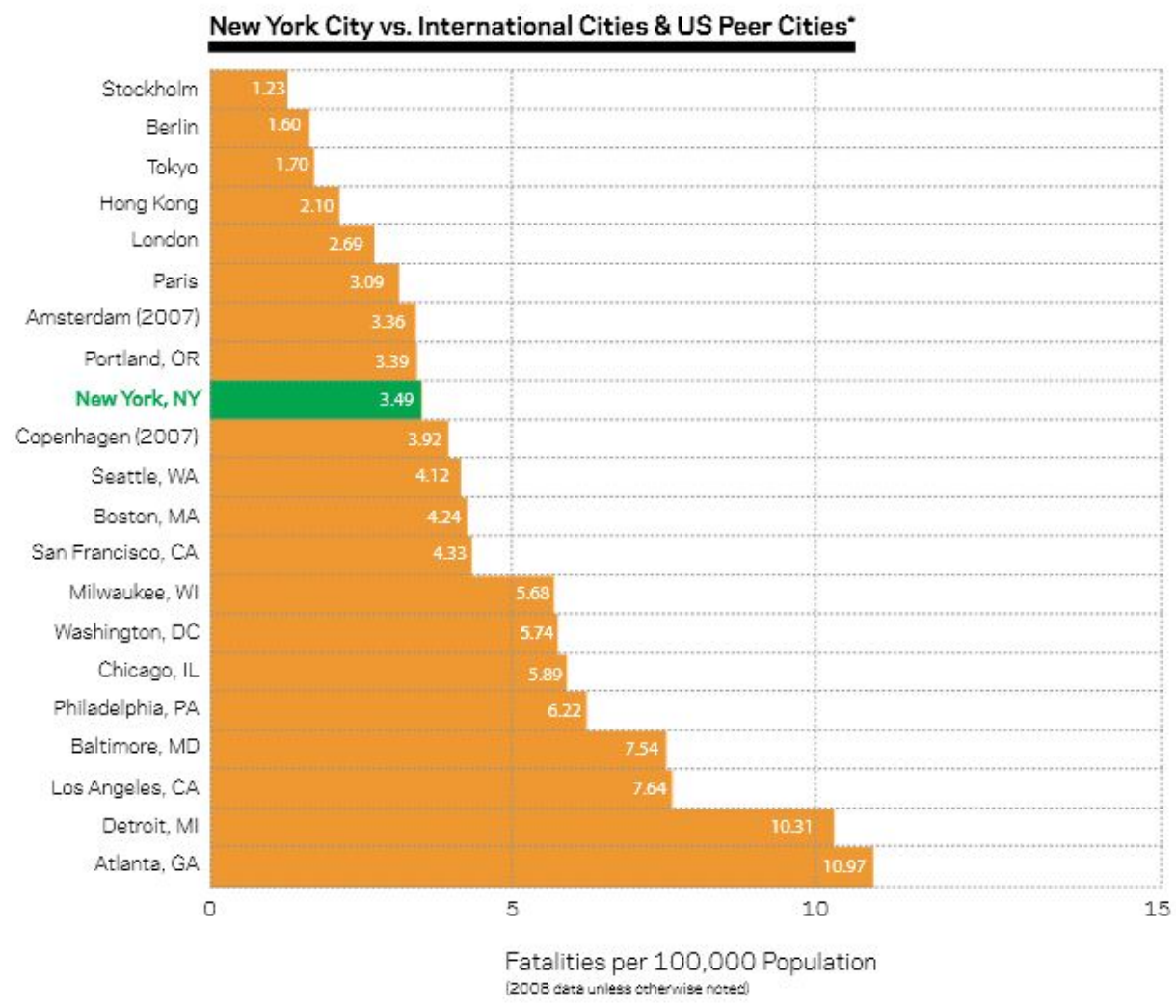

Figure 2: Traffic Fatalities for large U.S. Cities (New York City Pedestrian Action Plan, 2010)

than others, and in fact two American cities are comparable to European cities. As shown in figure 2, Portland, OR in 2008 had a traffic fatality rate of 3.39 FHPY, the lowest for a large city in the United States. While Portland still has a traffic fatality rate larger than most European cities, it is lower than Copenhagen and only slightly higher than Amsterdam, which has a traffic 
fatality rate of 3.36 FHPY, and Paris, with a traffic fatality rate of 3.09 FHPY. Portland has not always had such a low traffic fatality rate. Since 1986 traffic fatalities per 100,000 population have been decreasing 6 times faster than the U.S. average, as shown in figure 3 .
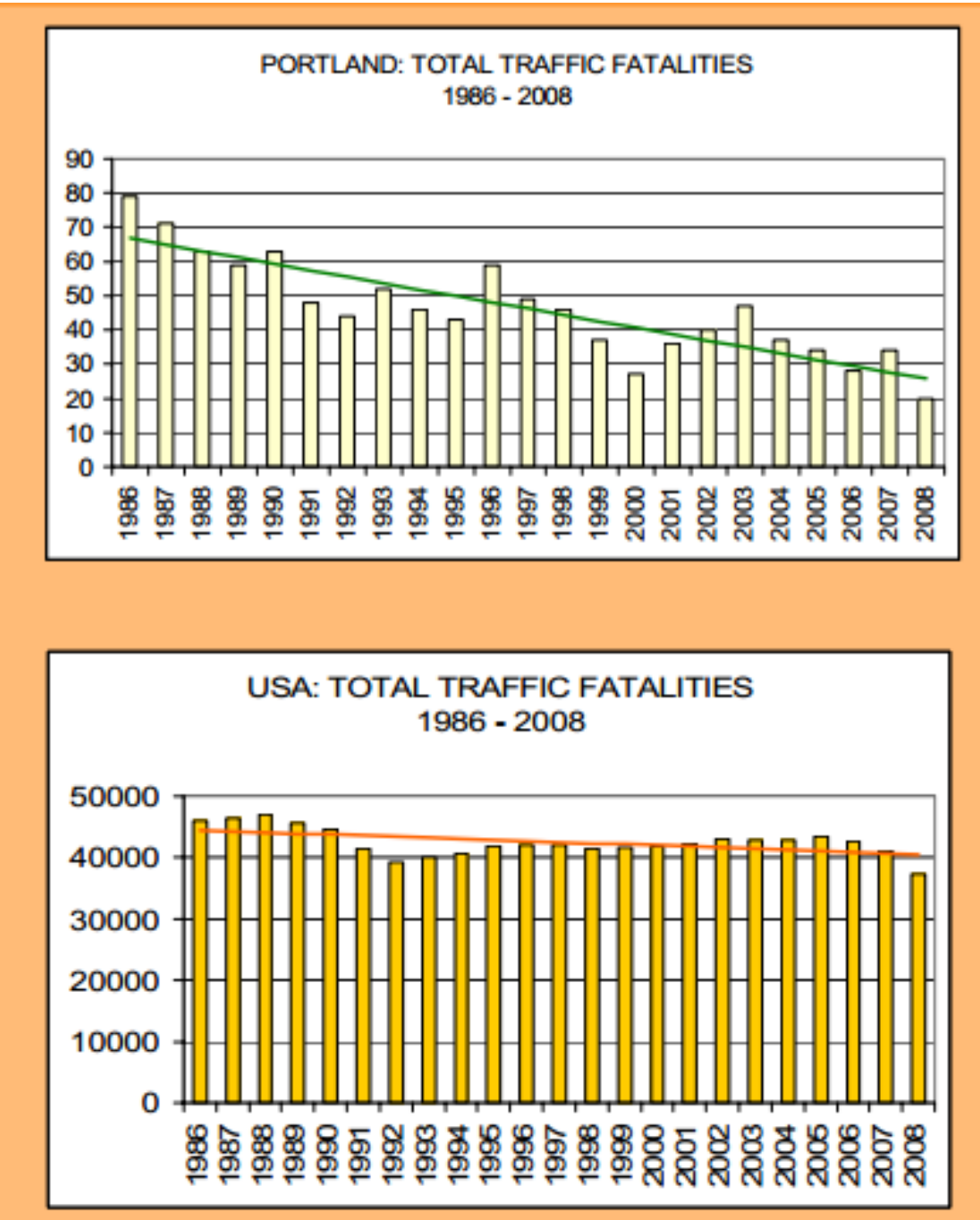

Figure 3: Portland Traffic Fatalities per population compared to US traffic Fatalities per Population (Greg Raisman, 2009) Retrieved from:

. http://www.portlandoregon.gov/transportation/article/267721 
Portland, compared to other American cities is very different to say the least. Charlie Hales, a transportation consultant and former Portland city commissioner, was quoted in the New York Times as saying that Portland is "the best European city in America" (2006, Baker).

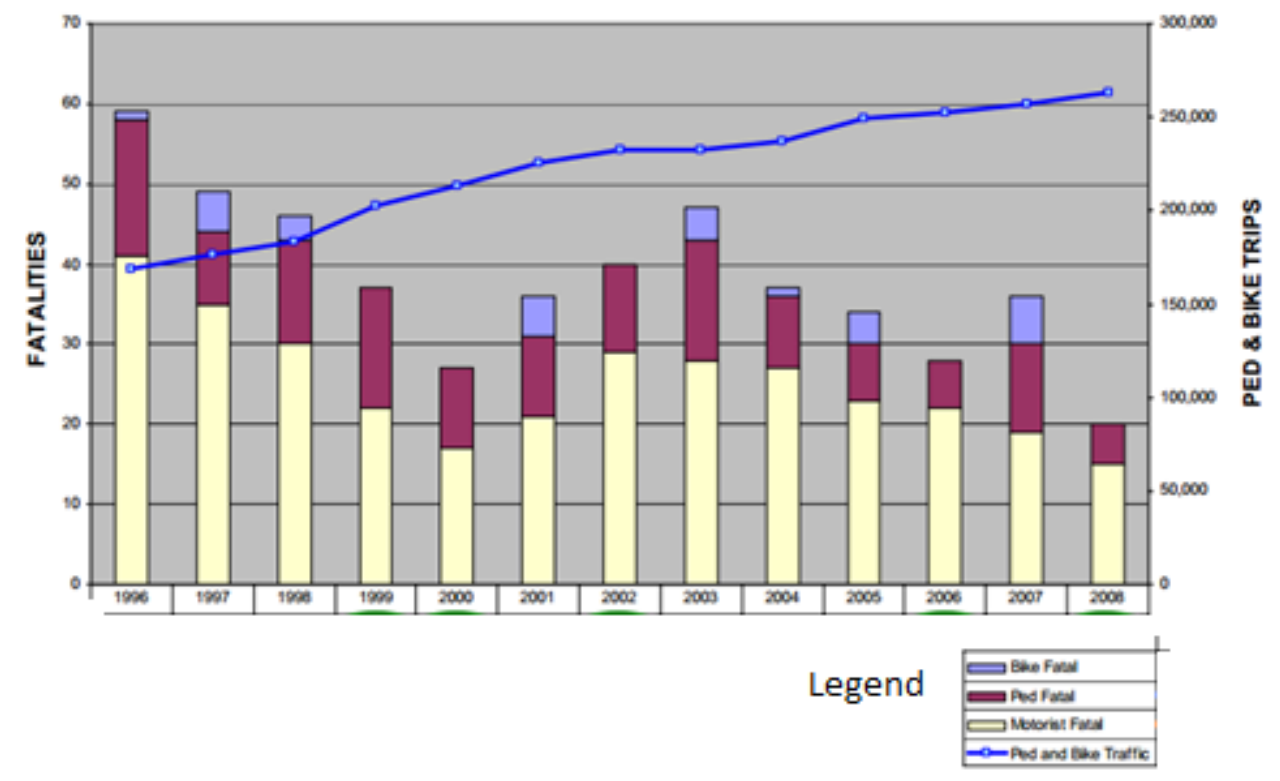

Figure 4: Traffic Fatalities in Portland compared to Pedestrian and Bike Traffic (Greg Raisman, 2009) Retrieved from: http://www.portlandoregon.gov/transportation/article/267721

Portland is very European in many regards: Portland is the first U.S. city to enact a comprehensive plan to reduce $\mathrm{CO}_{2}$ emissions and has aggressively pushed green building initiatives. Portland's regional planning body Metro has promoted transportation orientated development, high density and mix used development. Portland also has a comprehensive system of light rail, bus and bicycle ways. In the 1980's Portland had a transportation system like most other American cities, but since then large and aggressive changes have been made. While many things changed in that time period the most dramatic is the number of cyclists and cycling infrastructure. Bicycle use in Portland has been growing rapidly, having nearly tripled since 2001; for example, daily bicycle traffic on four of the Willamette River bridges has increased 
from 2,855 before 1992 to over 16,000 in 2008, partly due to improved facilities. Approximately $8 \%$ of commuters bike to work in Portland, the highest proportion of any major U.S. city and about 10 times the national average. As bicycling has increased in Portland, traffic fatalities for all modes of transportation dwindled.

New York City, a Changing Transportation System

Portland is not the only major U.S. city that has done major transportation changes to its overall system and seen remarkable safety rates as a result. New York City has the lowest traffic fatality rate among all U.S. cities with over one million in population. In 2012 New York City had record low traffic fatalities (New York City Department of Transportation, 2010). While the United States' traffic fatalities dropped by 24\% from 1990 to 2010, New York City's traffic fatalities dropped by 63\%. Since 2004, New York City's traffic fatalities has been lower than they were in 1910, the first recorded traffic fatalities for the city. Between 2001 and 2012 something else happened to the New York City traffic scene: bike ridership has tripled, from a 12 hour volume of 12,708 at screen line count locations to a 12 hour volume of 36,434 (NYDOT, 2012).

Bike Friendly Cities and Safety: Davis

Davis is about as opposite a city from New York City as any two cities can be, but they now have something in common. Davis is among the safest cities in the nation in terms of traffic fatalities, with an annual fatal crash rate of less than 2.1 per 100,000 residents, as shown in figure 5. This rate may be compared to the rest of the United States, whose annual average is 14.8 fatalities per 100,000 residents over that same time period (Marshall and Garrick, 2011). Davis, California is also the most bike-friendly city in the nation in terms of cyclists per population 
(Mapes, 2009). According to the 2010 census, 22\% of Davis residents commuted to work by bike. This is especially astounding when it is compared to the national average of $1 \%$ of workers who commuted to work by bike (census, 2010). This relationship between high bicycle modal split and low traffic fatalities is not an isolated phenomenon, this holds true for many other cycling-friendly cities. Portland, OR for instance has the lowest fatalities per population of any large city in the US (New York City Department of Transportation, 2010).

\section{Road Fatality Rate for All 157 California Cities Over 40,000}

number per 100,000 population

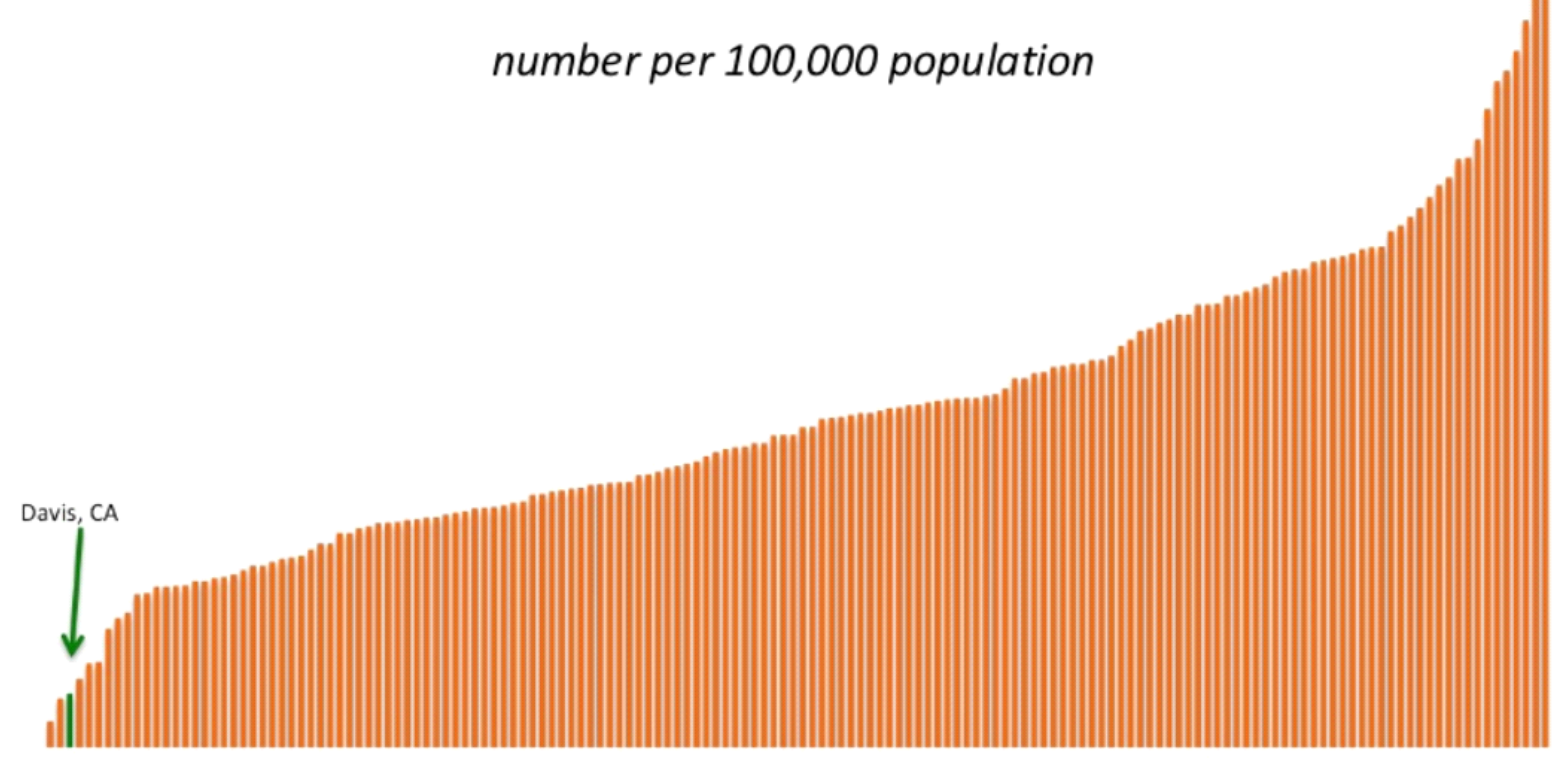

Data source: Marshall and Gerick, 2010

Figure 5: Traffic Fatalities for California Cities with a population over 40,000

In the past decade, biking has been on the rise in some California cities, according the census 2000-2010. This gives a unique opportunity to analyze this increased modal split and compare it against traffic fatalities. Previous research papers have explored the phenomenon that, 
as the number of cyclists in a city goes up, the safer that city is for cyclists (Jacobsen, 2003). But one study, done by Garrick and Marshall (2011) goes further, suggesting that more cyclists on the road, are safer for all road users (motorist, cyclists and pedestrians). Garrick and Marshall's paper focuses more on urban form as factor in traffic fatalities but doesn't isolate only bicycle modal split and cyclist's effect on traffic fatalities of all road users. This thesis further delves into that phenomenon and examines 20 years of traffic safety records and biking modal split to investigate the effect cyclists have on traffic fatalities and accidents in California cities. One of this paper's analyses focuses on how modal split changes over time and how that affects fatality rates over time. This paper's other analysis focuses on 30 different road segment sites within the City of San Francisco that have constructed a bike lane and study the before and after crash statistics to see if the installation of class II bike lanes have a measurable effect on safety.

\section{Build it and They Will Come}

One of the questions that this study seeks to answer is: if there is a relationship between bicycles and overall traffic safety; is this relationship due to bicycle infrastructure acting as a traffic calming measure, or is it the presence of cyclists that act as a traffic calming measure? This problem is further complicated with the fact that those two variables, bicycle modal split and bicycle infrastructure, are not independent of each other, as the city or Portland has documented. The article, "Build it and they will come", by Portland bicycle coordinator, Roger Geller, documents this phenomenon. Geller states that it was only when the City of Portland began building bicycle infrastructure that Portland's bicycle modal split began to outstrip the national average, suggesting that a city can only get people out of their cars and onto a bike if they build bicycle infrastructure. This is further collaborated with the fact that there are no cities 
that have a significantly larger bicycle modal split than the national average that has not invested extensively in bicycle infrastructure.

\section{Bikes and Safety}

Safety is a topic of great importance in promoting cycling. Safety is the most serious barrier to urban cycling and the promotion of cycling as a form of commuting. Safety concerns have been shown to be a major reason why people do not bike in American cities (Garrard et al., 2006; Goldsmith, 1992). This concern is dominated by the view that cycling is inherently a dangerous activity. This view is not entirely without merit. In 2008, 716 cyclists were killed and an additional 52,000 were injured in traffic crashes (NHTSA, 2009). This statistic is particularly concerning considering the fact that cyclists make up less than $1 \%$ of the traffic in America but account for $2 \%$ of all traffic deaths. This is a particular problem in the state of California, where bicycle fatality as a percent of the total number of fatalities is considerably higher than the national average, at 3.2\% (Alta Transportation Consulting, 2000). With the very real and known danger, it would logically follow that the majority of cyclists would use this knowledge and behave in a cautious and safe manner, but data shows that this is not the case. A study done by the University of North Carolina Highway Safety Research Center in 1996 found that a third of all bike accidents involve simply riding against the flow of traffic. Another study in Orlando found that between 2003 and 2004 nearly two thirds of the 803 cyclist crashes involved riding on the sidewalk, an act that is not only known to be unsafe but is against the law in most jurisdictions. These studies and others suggest that the majority of cycling deaths are avoidable. It also suggests that while most people know that cycling is a potentially dangerous activity, this knowledge does not translate into bikers behaving cautiously or safely. 
Bicycle Infrastructure and Bicycle Safety

A variety of studies have looked at the effects of bicycle infrastructure and bicycle safety. At first the conclusions were mixed, with most notably John Forester taking the position that bicycling was safer without infrastructure. Forester argued that cyclists were safer when they act and are treated like vehicle drivers. John Forester argued against separated bike lanes in Palo Alto saying it was safer for cyclists to behave as drivers. As Emily Badger from the Atlantic reports, "Research followed that seemed to reinforce Forester's idea: Biking in traffic did appear to be safer than many of its alternatives. But the alternatives that researchers had to examine in North America were unpaved routes, sidewalks, off-road and even mountain bike trails. At the time, we had little of the dedicated commuter bike infrastructure many cities are just creating now." But as more and more studies have been completed the consensus remains: bicycles are safer with bikeway infrastructure. The most notable of these researches is a paper by Harris and others (2009), who conducted a literature review based on 23 different studies. They came to the conclusion that bicycle infrastructure consistently improved safety for cyclists as compared to on-road cycling with traffic. They also concluded that class II and class III bicycle infrastructure were found to reduce injury by half as compared to roads without bicycle infrastructure (Harris, Teschke, Cripton, Winters, \& Reynolds, 2009).

While more studies have been done on Class II and Class III than on Class I bicycle infrastructure because there are significantly fewer Class I types in the United States, one federal study was done on the separated bike lanes on Broadway and Third Street in downtown Long Beach. The study found that with the new bicycle infrastructure, bike collisions dropped $80 \%$ and motor vehicle collisions went down $44 \%$. Average vehicle speeds also dropped from 36 to 
$27 \mathrm{mph}$ on Third Street and on Broadway vehicle speeds dropped from 30 to $36 \mathrm{mph}$. (Koa Cooperation Planning and Engineering, 2013)

The Relationship between Bicycle Infrastructure and Overall Safety

In many cases bicycle infrastructure doubles as a traffic calming device. New York City, for instance, has added 200 miles of bike lanes between the years 2006 and 2009, and has seen significant improvements to safety, not just for bicycles but for all road users. According to the New York City Pedestrian Safety Study and Action Plan, controlling for other factors, pedestrian fatal or serious injury crashes have decreased by $40 \%$ on streets with bike lanes. For example, after a parking-protected bike lane was installed on Manhattan's Ninth Avenue, all traffic-related injuries dropped 50 percent. Injuries to pedestrians dropped 29 percent and injuries to cyclists dropped 57 percent (New York City Pedestrian Safety and Action Plan, 2010). This is most likely because when a bike lane is installed on a street, the motor vehicle portion of the roadway usually narrows. These changes have a traffic calming effect, lowering speeds and increasing driver attention. A New York City study also examined the effect bike lanes have on adjacent traffic speeds and found that after a parking-protected bike lane went in on Brooklyn's Prospect Park West, incidents of speeding dropped 74 percent (Prospect Park West Bike Path and Traffic Calming Update, 2011).

A study in Canada also found similar results. After the city of Thunder Bay in Ontario, installed a number of bike lanes on streets they found that not only did bicycle and motorist crashes decrease, but also the total number of motorist collisions dropped. The motorist collisions dropped by 22 percent. The city's active transportation coordinator, Adam Kruppe (CBC News, 2013) stated that a narrower car lane was making motorists more cautious, even though traffic volumes hadn't changed. 
Edge line vs. Bike Lane

But is this decrease in fatalities due to the presence of bike infrastructure or the presence of cyclists? This question is further complicated by the fact that in many cities both bicycle usage and bicycle infrastructure tend to be directly related. In New York City, for instance, commuter cycling has increased by $26 \%$ between 2008 and 2009 and more than doubled since 2005 in the same period that 200 miles of new bike lanes were installed (New York DOT, 2013).

An answer to this dilemma might be found by comparing bicycle lanes to the installation of an edge line. An edge line is a painted line several feet away from the edge of the roadway and has the effect of visually narrowing the roadway. The ITE publication, "Traffic Calming: State of the Practice", explains: "In theory, the perceived narrowing could cause a modest speed reduction, just as a real narrowing causes a modest speed reduction. The theory is not borne out by empirical studies. Results from Howard County, MD, Beaverton, OR, and San Antonio, TX, suggest that vehicle operating speeds are as likely to increase as decrease with striping. One explanation is that centerlines and edge lines define the vehicle travel path more clearly, creating a gun barrel effect. Results from the aforementioned studies could be dismissed because even with the narrowing, pavement and lane widths remained substantial. Yet, results from Orlando, FL, where travel lanes were taken down to 9 feet, showed speeds to be unaffected.” (ITE, 1999)

The ITE publication goes on to describe an exception to this rule, the North Ida Avenue project in Portland. This project differed from the other studies, in that the restriping didn't just narrow the roadway but added a bike lane. The narrowing of this lane due to restriping was found to reduce $85^{\text {th }}$ percentile speeds by $2.0 \mathrm{mph}$. Whether this restriping and narrowing proved 
more effective because it created bicycle lanes rather than shoulders, or because it was coupled with physical measures, is an issue for further study.

Safety in Numbers for Motorists and Smeed's Law

The idea of 'safety in numbers' is a well-documented idea in the field of transportation. It was first theorized in 1949 by R. J. Smeed. Smeed noticed an interesting statistical phenomenon about traffic fatalities when investigating traffic around the world, which is still evident today. This phenomenon is clear when comparing China and the United States traffic deaths across nearly 50 years of data. In 195135,309 people were killed in traffic fatalities in United States. In that same year, across the world in China only 852 people were killed in traffic. 48 years later, in 1999 traffic fatalities in the United States modestly rose to 41,508 , while the same figure in China dramatically rose to almost 84,000 (Vanderbilt, 2008). Why did the number of traffic fatalities grow so dramatically in China than in the United States?

In China the number of cars rose significantly, but so did the number of cars in America. In 1999, while there were 50 million vehicles in China, there were 200 million vehicles in America. Despite having 4 times as many motor vehicles, twice as many motor vehicle deaths happened in China than in the United States.

This phenomenon has become known as 'Smeed's Law.' Smeed analyzed 62 different countries and found that road fatalities rose in countries as the number of vehicles rose, then after reaching a tipping point, fatality rates begin to drop, and after a time, the total number of fatalities would begin to drop. This relationship is shown in figure 2 (Smeed, 1949). Smeed concluded that this happened for two reasons. First, that after more and more people were killed in traffic fatalities, a point would be reached that public outcry would demand safer roads, vehicles, enforcement and policy. Such a point was reached in the United States in the 1960s 
when total national fatalities reached 50,000 traffic deaths. Secondly, he concluded that after vehicles became more and more common, a national learning curve was established, such that people learned to drive safer, traffic laws became more established and enforced, and roadway engineering became better.

The ideas of 'Safety in numbers' not only applies to motorists but, as many studies have shown, to cyclists and pedestrians as well. Rune Elvik's paper, The Non Linearity of Risk and the Promotion of Environmentally Sustainable Transport (2009) summarizes nine studies done between 1998 and 2003 that document the risk of injury to pedestrians and cyclists. He found that the more pedestrians and cyclists there are, the lower the risk each individual pedestrian or cyclists face.

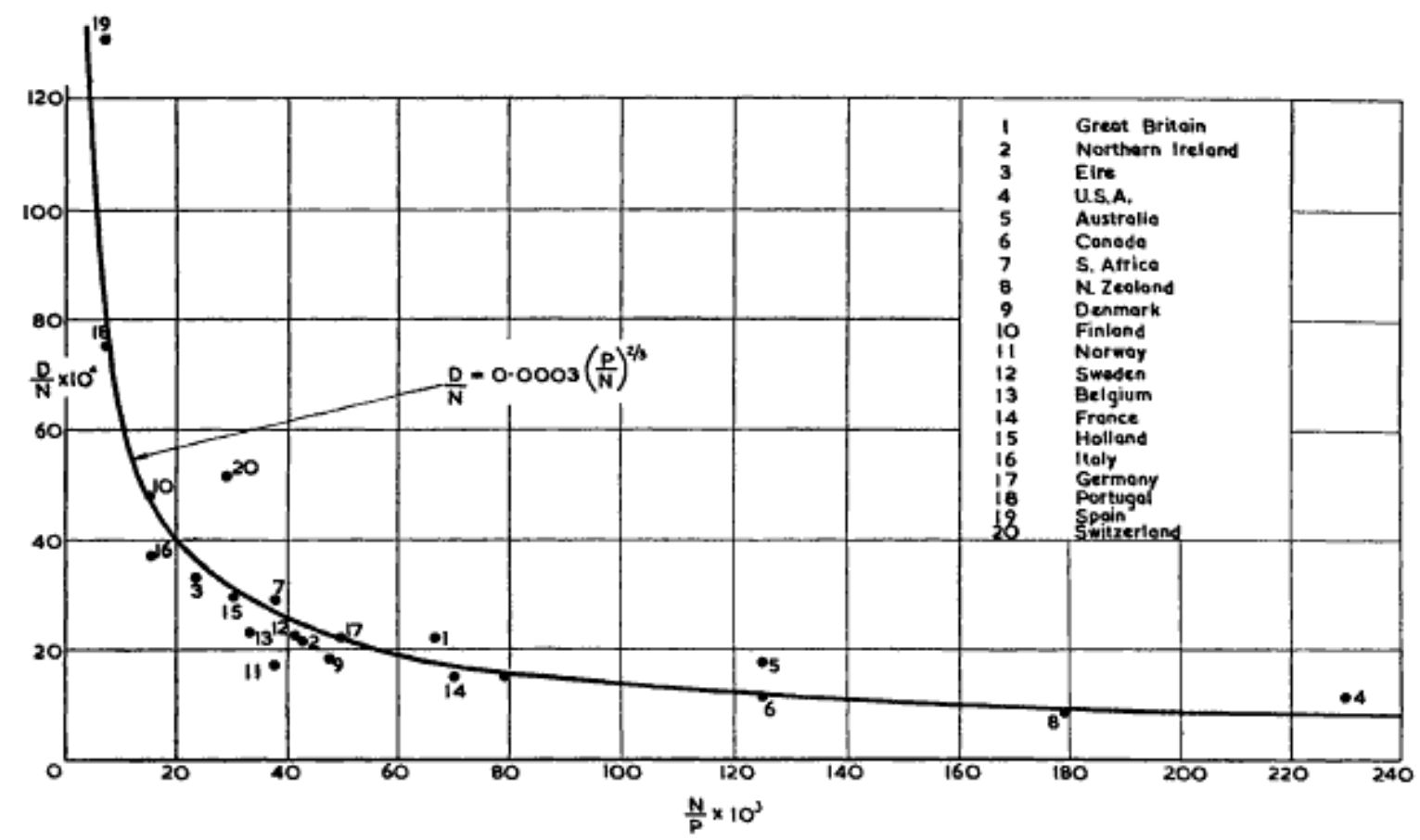

FIG. 1A

Relation between Number of Deaths per 10,000 Registered Motor Vehicles and Number of Vehicles per 1,000 Population for 1938

Source: Smeed, 1949

Figure 6: Smeed's Law 
Motorist's Behavior and Fatalities

A great many things affect traffic fatalities: weather, age, intoxication levels, gender, public policy, police enforcement and road design, to name a few. But some factors affect traffic fatalities more than others, and two factors affect the risk of an individual most. Leonard Evans argues that, "two factors that overwhelmingly determine an individual's risk in traffic are: an individual's behavior and the behavior of other road users."(Evans, 2004, pg. 413) He goes on to say that, "It is important for road travelers to understand more clearly that it is the safety of the traffic system, and particularly the way vehicles are driven that is crucial, not how vehicles perform when they crash" (Evans, 2004, Pg. 415). If how vehicles are driven and particular human behavior while driving, is the most important factor in traffic safety, exploring the psychology behind driving is of paramount importance in the field of transportation safety.

Bicyclist's Behavior and Safety

The importance of individual behavior in terms of traffic fatalities isn't a new concept and is true not only for motorists but also for cyclists and pedestrians as well. A cyclist safety advocate, John Forester, wrote in his book, Effective Cycling, principles of how cyclists should behave to keep themselves safe. John Forester advocates that cyclists are safest when they behave like a motor vehicle, lending the name vehicular cycling to his method. Forester presents a number of rules that cyclists should follow that are indeed well known to keep cyclists safe; the rules include: cyclists keeping out of the door zone, not weaving in and out of parked cars, staying to the left of right hand turn lanes if the cyclist is going straight when at an intersection 
and moving to the middle of the car lane rather than staying to the right as much as possible when a situation warrants it.

\section{Safety and Inattention Blindness}

Driving is a very visually oriented activity. The ability to maneuver through a city is dependent on seeing traffic signals, stop signs, lane markers, other vehicles as well as pedestrians and bicycles. Since humans use the sense of sight regularly, it is an ability we take for granted and assumes that we are very good at, but the field of psychology has a large and growing body of research that indicates otherwise. Simon and Charis (1999) have done numerous experiments on the matter, and state that "When attention is diverted to another object or task, observers often fail to perceive an unexpected object, a phenomenon termed 'in-attentional blindness' (e.g. Mack and Rock, 1998)." Transport for London has stated that research suggests inattention blindness is possibly the reason why motorists collide with cyclists. When involved in an accident, motorists and cyclists may say that a car or bike, "came out of nowhere" when in reality the car or bike was operating normally. When driving, motorists and cyclists tend to fixate on one thing, whether it be the road ahead, the light that might turn yellow, the turn they can't miss, or the vehicle in front of them.

This same idea is also prevalent when drivers see something they might not expect; it takes longer for them to react to it. People tend to see what they expect to see; people watching a basketball game don't expect someone in a gorilla suit, so they gloss over it when it happens. A driver in Maine will break faster for a moose than for a penguin. This is also true for cyclists. If a motorist looks out a drive way that he has driven by every day, even if there is a cyclists there, if the motorists isn't used to seeing a cyclists he might not actually see the cyclists. This tendency 
explains the safety in numbers effect. As more cyclists exist in a city the more motorists will tend to watch out for them and become accustomed to their movements.

Driving in a Snow Storm, Risk Compensation and Risk Homeostasis

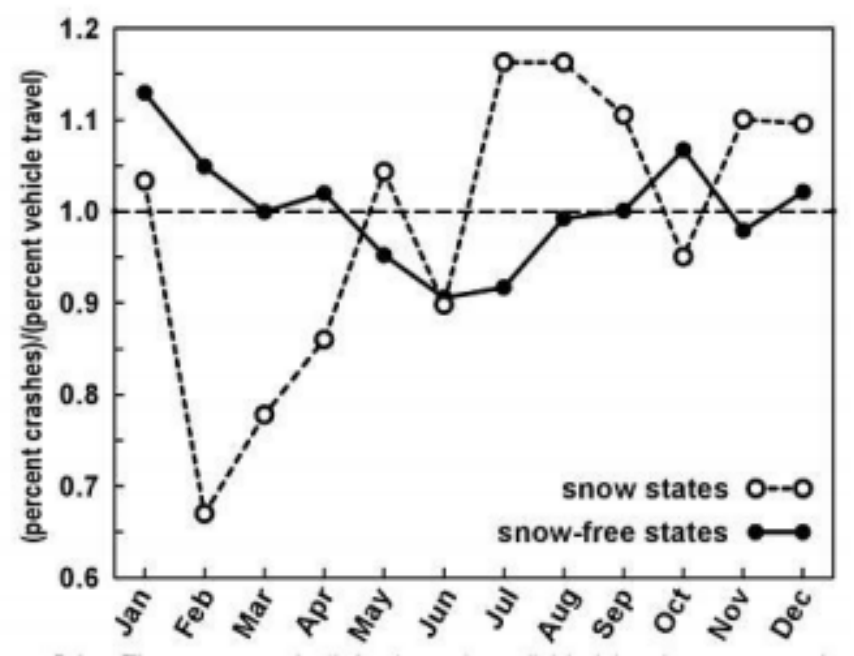

Figure 7: The percent of all fatal crashes by the percent of rural distance of vehicles traveled for snow and snow-free states. FARS 2001 (Evans, 2002, p.100)

A topic of importance when discussing traffic safety is the idea of risk homeostasis, this idea is clear when looking at how people drive in the snow. Driving in the snow seems daunting, particularly for a southern California resident. If given the option of driving on a road covered in snow or a road free from all weather related hazards, the latter is likely to be the preferable option. One definitely appears to be safer but, as science has repeatedly shown, the human brain is easily deceived. Crash statistics show that while the number of collisions on snow days, relative to clear days, go up, fatality rates go down, in states that are unfortunate enough to not have California's idyllic climate, as shown in figure 7. In February the fatality rate, as calculated by Leonard Evans (Evans, 2002, 100), is $43 \%$ less than the average yearly fatality rate. While it can be said that people tend to drive less in February in snow states, data from rural arterial 
streets were used to calculate the reduction in vehicle miles traveled, even with this factored in the data is still clear: when the road is covered in snow fatality rates dramatically drop.

This phenomenon is called risk homeostasis and was first documented by the physiologist Gerald Wilde. It presents a strange but intuitive phenomenon; that safety can lull you to act more dangerously (Lewis-Evans and Charlton, 2006; Mok et al, 2004).

Bikes and their effect on Traffic Behavior

Some have speculated that the presence of bikes and bike related infrastructure has acted as a form of traffic calming, changing the behavior and attitudes of motorists. As Jeff Mapes observes in his book, Pedaling Revolution, "around Davis... the drivers are incredibly mellow. They surrender the right of way with the same eagerness that people open doors for someone in a wheel chair" (Mapes, 2009, 119). Other studies have shown that motorists get used to many forms of traffic calming, such as traffic signs, but bikes are moving obstacles that keep motorist alert and aware. Peter Jacobsen (2003) also echoes the idea that motorist behavior changes, saying that an increase in cyclists leads to "a strong response to motorists, if the motorist expects to see someone walking or biking, he will behave accordingly" (Mapes, 2009), Todd reported three studies showing "motorists in the United States and abroad drive more slowly when they see many pedestrians in the street and faster when they see few" (1992).

While the very presence of pedestrians and bicycles may calm traffic, infrastructure also plays a key role in this phenomenon as well. As Marshall and Gerick conclude, "ultimately 'safety in numbers' does not just happen”. Instead, their research suggests that the same strategies that attract bike riders are the same ones that improve road safety for all road users. (Marshall, Gerick, 2011) These strategies include tree lined streets, shorter block lengths, lower speed limits and urban density. 


\section{Bicycle Infrastructure as a Traffic Calming Measure}

Another contributing factor to the safety and bicycle modal split relationship may well be that bicycle infrastructure in many ways doubles as a traffic calming measure. There are many different types of bicycle infrastructure; certainly some types, such as class I off-road bike paths, do not act as a traffic calming measure. But some, such as bicycle boulevards and road diets, do.

Bicycle boulevards are roads that give priority to bicycles and are optimized for bicycle traffic. They are low-speed roads that discourage through movement of motor traffic. This discouragement, when done correctly, lowers motor vehicle volume and speed that could have a corresponding safety benefit, though since bicycle boulevards are a recent phenomenon no study has investigated its safety affects.

Road diets are another tool that bicycle advocates use to change the street system to be more bicycle friendly. Large, wide, high speed roads are intimidating to cyclists and can be unsafe for motorists and bicyclists alike. Transportation engineers and safety specialists have long known that overloaded two-lane or four-lane roads of any volume can be risky places to drive, conduct business, attempt to access transit, walk or bicycle. On such roadways, frequent turning movements into commercial and residential driveways can result in high crash levels. On multi-lane roadways lane swapping adds friction and reduces performance.

\section{Characteristics of Bicycle Friendly city that Contribute to Traffic Safety}

There are a number of other characteristic of bicycle friendly cities, other than bicycle infrastructure, that also contribute to their lower than average traffic fatalities. They include population density and road network density. 
Another contributing factor, to a slightly lesser extent, could be density. Density is a moderately good predictor of traffic fatalities (Clark, Cushings, 2004). As density goes up, traffic fatalities per population tends to go down, although this is not true in all cases. For instance, in very high density places such as San Francisco this notion does not hold true, but in rural areas and moderately dense cities it does. Cyclists also prefer higher density cities in general. While this does not always hold true, it makes intuitive sense especially considering that $60 \%$ of trips on a bicycle are 1 mile or less (U.S. Department of Transportation and Federal Highway Administration, 2009).

\section{Chapter 3: Methodology}

Citywide Analysis

The objective of this research is to understand the community-wide safety impacts of biking, and the effects of biking infrastructure and people biking on motorists and traffic safety as a whole. To gain a comprehensive look at bicyclist's effect two analyses were done, a citywide analysis and a site base analysis.

\section{Initial Database}

While many European countries have been the subject of many biking safety research papers, few studies have been undertaken in the United States. California remains one of the states in the U.S. that have been the subject of similar studies. Both P. T. Jacobsen and Gerick and Marshall's research included only California cities. While other states have the potential to be the subject of research, Oregon and Colorado mainly, California presents a unique opportunity. It is a very large state, and has a wide range of cities to analyze; it has a few very large cities like Los Angeles, San Francisco and San Diego, and also has a wide range of biking 
cities. Some cities in California, like Davis and Palo Alto, have whole heartedly embraced biking, some cities like Sacramento and Pasadena, have started to encourage biking, and some cities have continued with the status quo, giving the State a good mix of cities to choose from. Cities were also only chosen from California to allow a relatively consistent comparison.

A number of questions needed to be answered when picking the cities to include in this research. If there was a correlation and relationship between bicycle modal split and fatalities what are the upper and lower bounds? What was the minimum number of cyclists before the infrastructure and bicycles themselves started to affect the traffic system as a whole? The statistics about Portland and Davis suggest that if there is an effect it is after an increase in bike modal choice, but is only one cyclist enough to change it, or is there a critical mass necessary to invoke a change in a city, and if so what percentage is that critical mass? A large enough city sampling was looked at to ensure that a lower bound could be established.

Table 1: Selected Biking Cities

\begin{tabular}{|c|c|c|}
\hline $\begin{array}{l}\text { Biking Modal } \\
\text { Split }\end{array}$ & 2000 & 2010 \\
\hline \multicolumn{3}{|c|}{ High Biking City } \\
\hline Davis & $14.4 \%$ & $22.1 \%$ \\
\hline Arcata & $5.2 \%$ & $10.1 \%$ \\
\hline Palo Alto & $5.6 \%$ & $8.6 \%$ \\
\hline Santa Cruz & $4.4 \%$ & $8.5 \%$ \\
\hline \multicolumn{3}{|c|}{ Medium Biking City } \\
\hline Berkley & $5.6 \%$ & $8 \%$ \\
\hline Chico & $5.2 \%$ & $5.5 \%$ \\
\hline Santa Barbara & $3.4 \%$ & $6.4 \%$ \\
\hline San Luis Obispo & $3.6 \%$ & $5.2 \%$ \\
\hline \multicolumn{3}{|c|}{ Low Biking Cities } \\
\hline Pasadena & $1.4 \%$ & $4.8 \%$ \\
\hline San Francisco & $2 \%$ & $3.5 \%$ \\
\hline Mountain View & $2 \%$ & $4.1 \%$ \\
\hline
\end{tabular}


478 California cities. California has one law governing traffic, consistent traffic control devices, similar driving behavior, and one database for traffic collision and fatality data. From that initial data base cities were filtered out based on their populations. Cities with a population less than 10,000 in 1990 were removed because the population was not large enough to produce fatality and accident data that formed meaningful averages, and to make the data more manageable. This left a database of 286 cities.

\section{Modal Split}

The US Census Bureau collected journey to work trip data for the year 2000 and 2010. While such trips constitute only a fraction of all person trips, this analysis assumes that the mode for journey to work is in proportion to the mode for other purposes.

The data was further broken down into four categories: high biking cities, medium biking cities, low biking cites and non-biking cities. These categories were determined by the modal split taken from Census journey-to-work data in 2010. High biking cities fall within the range of $>8 \%$ biking to work in the year 2010, medium biking cities fall within the range of $5 \%$ to $8 \%$ biking to work in the year 2010, and low biking cities are within the range of 3\% to 5\% biking to work in the year 2010. The results are shown in figure 8 . These cities were then compared to the non-biking cities in California. A comparison of the modal splits of California as a whole and selected bicycle cities is shown in table 1 . Table 1 shows general trends in modal split, including the increases in biking as a whole in California, the increase in walking, and the decrease in public transit use and vehicle use. 


\section{Bicycle Modal Split for \\ Select CA Cities}

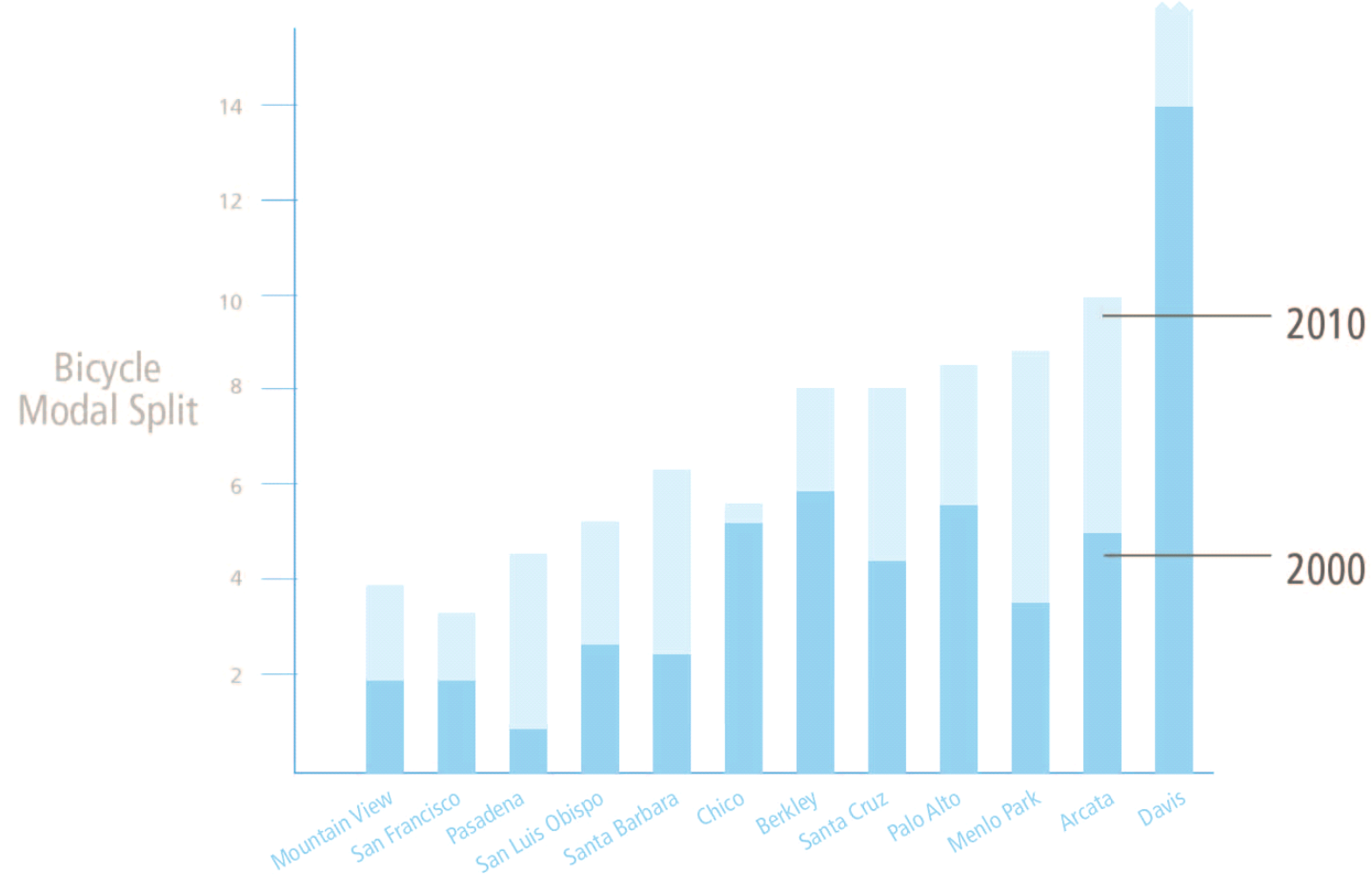

Figure 8: Bicycle Modal Split for Selected California Cities (Census, 2010)

Crash Data

This paper will then look at 20 years of fatalities from 1990 to 2010. This information is obtained by the California Highway Patrol Annual Report of Fatal and Injury Motor Vehicle Traffic Collisions. It will then compare and analyze the difference between the cities that have biking as a prominent mode of transportation and see if their traffic fatalities go down at a faster rate than cities without biking. 
Fatality data will also be compared to a city's density, median household income, average commute time, and modal split for walking, public transit, and motor vehicle.

Table 1: 2000 and 2010 Mode Choice: State of California vs. Bike-Friendly Cities in the State

\begin{tabular}{|l|r|r|}
\hline Variable & 2000 Mean & 2010 Mean \\
\hline California Average & & \\
\hline Vehicle Modal Split & $88.6 \%$ & $86.9 \%$ \\
\hline Walking Modal Split & $2.6 \%$ & $3.4 \%$ \\
\hline Transit Modal Split & $4.1 \%$ & $3.8 \%$ \\
\hline Bicycle Modal Split & $0.9 \%$ & $1.1 \%$ \\
\hline Other & $3.8 \%$ & $4.8 \%$ \\
\hline $\begin{array}{l}\text { Selected } \\
\text { Cities }\end{array}$ & & \\
\hline Behicle Modal Split & $74.4 \%$ & $69.7 \%$ \\
\hline Walking Modal Split & $7.2 \%$ & $7.1 \%$ \\
\hline Transit Modal Split & $7.7 \%$ & $8.1 \%$ \\
\hline Bicycle Modal Split & $4.7 \%$ & $8.0 \%$ \\
\hline Other & $6.0 \%$ & $7.1 \%$ \\
\hline Souce Census, $2010 ; C e n$ & $200 \%$ & \\
\hline
\end{tabular}

Source: (Census, 2010; Census, 2000)

Statistical Analysis

After compiling the data a regression analysis was completed using SPSS. The analysis determined if there was a distinguishable relationship between traffic fatalities and bicycle modal split and what type of a relationship it is, whether linear, exponential, power or another type.

Site Based Analysis

The site based portion of this analysis was done to get a closer look at the effects of bicycle on traffic safety, and specifically the effects of cycling infrastructure on traffic safety rather than modal split. Conducting a site based analysis also eliminates other variables and isolates just the effects of the addition of bicycle infrastructure on the crashes of a particular street. Since the site based analysis portion analyzes a much smaller area than the citywide 
analysis, both fatal and non-fatal crashes were looked at in this section in order to get a larger amount of data points. The site based analysis focused exclusively on the City of San Francisco. San Francisco was uniquely situated to be the subject of this study because of its size and the amount of data available to complete the analysis.

The Empirical Bayes Method using the Highway Safety Manual

The 2010 Highway Safety Manual (HSM) was used to estimate the expected average crash frequency of the individual sites chosen in this analysis using the Empirical Bayes method. The Empirical Bayes method combines two different sets of data to estimate the number of crashes at the treated sites: the crashes at the treatment site in the before period and the crash frequency expected at reference sites (Hauer, 1997), which can be written in the mathematical form as in equation 1 (Hauer, 1997):

$$
E=\left(y_{i} \times n\right)+\left(1-W_{i}\right) n_{i} \quad \text { Equation } 1
$$

Where $\eta_{i}=$ Observed number of crashes at the treatment site during the before period $n=$ Number of years in the before period

$y_{i}=$ Number of average expected crashes of given type per year estimated from the safety performance function (SPF)

And $W_{i}=$ the weight parameter

$$
\begin{array}{ll}
W_{i}=\frac{1}{1+k \times y_{i} \times n} & \text { Equation } 2
\end{array}
$$

$k=$ Dispersion parameter

The data from the reference sites is obtained as output from the safety performance function (SPF), which is a regression model that provides an estimate of crash occurrences on a 
given roadway section. Crash frequency on a roadway section may be estimated using negative binomial regression models (Abdel-Aty and Radwan, 2000; Persaud, 1990). Therefore it is the form of the SPF for negative binomial model that is used to fit the before period crash data of the reference sites with their geometric and traffic parameters. A typical SPF will be of the following form using the crash data from the before period of the reference group:

$$
y_{i}=e^{\left(\beta_{0}+\beta_{1} x_{1}+\beta_{2} x_{2}\right)} \quad \text { Equation } 3
$$

Where $\beta_{i}$ 's $=$ regression parameters,

$$
\begin{aligned}
x_{1} & =\log (\mathrm{AADT}) \\
x_{2} & =\text { road segment length in feet }
\end{aligned}
$$

Over-dispersion parameter, denoted by $k$ is the parameter which determines how widely the crash frequencies are dispersed around the mean. This is used to estimate the relative weight of the two sets of evidences.

And the standard deviation $\left(\sigma_{i}\right)$ for the estimate is given by:

$$
\sigma_{i}=\sqrt{\left(1-W_{i}\right) \times E_{i}} \quad \text { Equation } 4
$$

Normally the Empirical Bayes method requires that the final estimated number of crashes at the treatment location be adjusted for traffic volume changes and different time periods, but for this analysis the same period of time was used in the before and after period ( 5 years), and data for volume was only available for one period for all of the sites used in this analysis so no adjustment was needed.

The index of effectiveness $\theta$ of the treatment is given by:

$$
\theta=\frac{L / \pi}{1+\left(\sigma^{2} / \pi^{2}\right)} \quad \text { Equation } 6
$$

Where, $\mathrm{L}=$ Observed number of crashes at the treatment site during the after period. 
The percentage reduction $(\tau)$ in crashes at each site is given by:

$$
\tau=\left(1-\theta_{i}\right) \times 100 \% \quad \text { Equation } 7
$$

The effectiveness $(\theta)$ of the treatment averaged over all projects involving the same treatment would be given by (Persaud, B., Retting, R., Lyon, C., 2004):

$$
\theta=\frac{\sum_{i=1}^{m} L_{i} / \sum_{i=1}^{m} E_{i}}{1+\left(\operatorname{var}\left(\sum_{i=1}^{m} E_{i} /\left(\sum_{i=1}^{m} E_{i}\right)^{2}\right)\right.} \quad \text { Equation } 8
$$

Where, $m=$ total number of projects involving the same type of treatment.

If $\theta$ has a value of less than one, then the treatment is estimated to have a positive effect on safety. The percent change in collisions is $100 *(1-\theta)$. A 95 percent confidence interval for $\theta$ can be estimated by computing the standard error of $\theta, \operatorname{se}(\theta)$, with the following formulae:

$$
\begin{array}{ll}
\operatorname{Var}(\theta)=\sqrt{\frac{\theta^{2}\left[\left(\frac{\operatorname{var}(E)}{\sum E^{2}}\right)+\left(\frac{\operatorname{var}(L)}{\sum L^{2}}\right)\right]}{\left[1+\frac{\operatorname{var}(E)}{\sum E^{2}}\right]^{2}}} & \text { Equation } 9 \\
\operatorname{se}(\theta)=\sqrt{\operatorname{var}(\theta)} & \text { Equation } 10 \\
\text { Confidence Interval }=\theta *(1.96 \mp \operatorname{se}(\theta)) & \text { Equation } 11
\end{array}
$$

To determine if the results of the Empirical Bayes method is statically significant, the 95 percent confidence interval is calculated using equation 9. If $\theta<1$ and the 95 percent confidence interval does not contain 1 , then the results are statically significant.

Bike Lane Site Selection 
The first step of this analysis involved defining the bike lane test sites and their roadway limits. The sites selected have to be homogenous roadway segments. A minimum of 20 sites were needed to have enough data to reach a statistically meaningful conclusion. This analysis focuses solely on sites with class II bike lanes. Sites were also chosen such that the bike lane was constructed between the years 2004-2009, so that adequate crash data was available to analyze the before and after effects of the bike lane's construction. The sites were also only selected from the city of San Francisco. This was primarily done because the city of San Francisco is large enough to have built 30 bike lanes in the years specified. Originally this study was going to include sites from many different cities throughout California but it was narrowed only to San Francisco because many cities do not keep accurate or well organized records of the exact year when bike lanes were built. Having the data come from only one city has the advantage of having a level of consistency through the data, so that many external factors are constant throughout the data such as weather patterns, traffic laws, and, to some extent, driver behavior.

In addition to the 20 bike lane sites, 25 control sites were also chosen. The control sites were chosen semi randomly. They were chosen so that they were in the same general areas as the bike lane sites; they were also chosen so that their traffic volumes fell into a similar range as the bike lane sites; and they were also chosen so that they were similar in length to the bike lane sites.

\section{Crash Data}

Crash data for this section of the analysis was obtained from UC Berkeley's transportation injury mapping system (TIMS). TIMS, which was established by the Safe Transportation Research and Education Center (SafeTREC), geocodes all crash data and maps 
the collisions for the state of California. Crash data is available for the years 2002 to 2011, yielding 10 years of crash data that was used for this study. Figure 9 shows an image generated by TIMS depicting crashes in the city of San Francisco from 2002 to 2011 that are represented in a heat map. The red areas have the most crashes and the green and blue areas have the least crashes. Only fatal and injury crashes were used in this study. Property damage only (PDO) crashes were not included because of their subjective nature. Many PDO crashes are not reported making that data unreliable. Underreporting PDO crashes presents a drawback to current crash data. Fatal and injury crashes are required to be reported in the State of California, but PDO crashes are reported only if the crash results in a certain amount of damage (e.g., $\$ 1,000)$ or if a vehicle is towed from the scene (Highway Safety Improvements Program Manual, 2010).

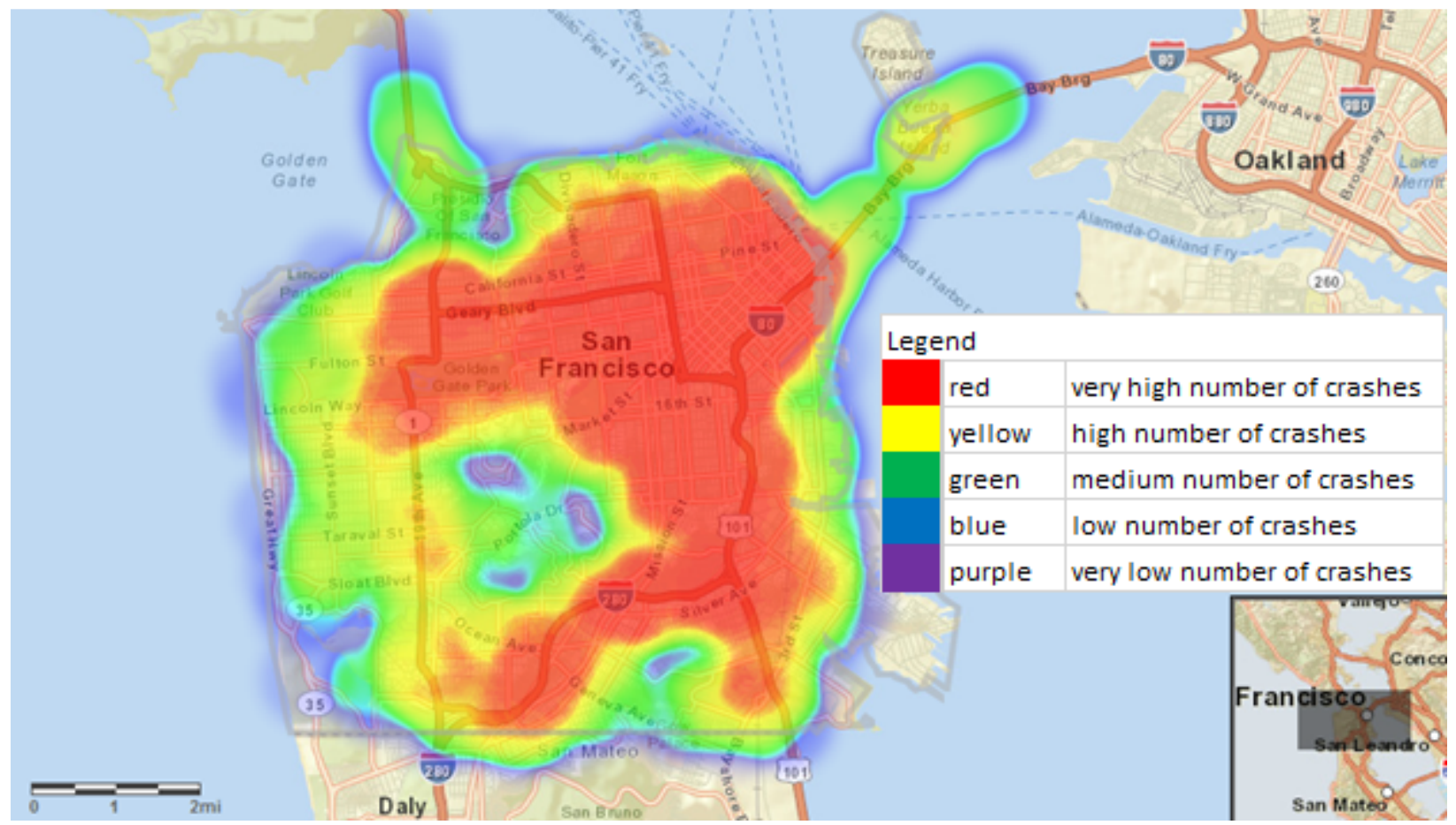

Figure 9: San Francisco Traffic crashes depicted as a heat map (TIMS, 2013) 
Traffic Volumes

To complete this study's analysis the average annual daily traffic (AADT) volumes in vehicles per day were obtained. AADT was found on SFMTA's website in a report entitled, “SFMTA Traffic Count Data 1993 - 2003" for all analysis sites and is summarized in Table 2. Since AADT was found for only one year, the same value is assumed to apply for all years during the analysis period.

Table 2: Selected Sites for analysis

\begin{tabular}{|c|c|c|c|c|c|}
\hline & Site & $\begin{array}{c}\text { Cross Street } \\
\text { Start }\end{array}$ & Cross Street End & $\begin{array}{l}\text { Volume in } \\
\text { AADT }\end{array}$ & $\begin{array}{c}\text { Control } \\
\text { Site/Bike lane } \\
\text { Site }\end{array}$ \\
\hline 1 & Harrison & Treat Ave & 17th St & 10030.0 & Bike lane Site \\
\hline 2 & Oakdale & Quint St & Industrial St & 10519.0 & Bike Lane Site \\
\hline 3 & Oakdale & Newhall St & Dunshee St & 10519.0 & Bike Lane Site \\
\hline 4 & Fulton & Pierce St & Scott St & 11977.0 & Bike Lane Site \\
\hline 5 & Turk & Stanyan St & Willard North St & 11989.0 & Bike Lane Site \\
\hline 6 & Market & Valencia St & Octavian St & 12670.0 & Bike Lane Site \\
\hline 7 & Bryant St & $3^{\text {rd }}$ & 2nd St & 12841.0 & Control Site \\
\hline 8 & 16th St & Guerrero & Dolores & 13329.0 & Control Site \\
\hline 9 & Mission St & Ocean Ave & Russia Ave & 14340.0 & Control Site \\
\hline 10 & Mission St & Cotter St & Alemany & 14340.0 & Control Site \\
\hline 11 & Mission St & Cotter St & Ocean Ave & 14340.0 & Control Site \\
\hline 12 & 16th St & Shotwell St & Capp St & 14423.0 & Control Site \\
\hline 13 & Arguello & Sacramento St & California St & 14501.0 & Bike Lane Site \\
\hline 14 & Bush St & Pierce St & Divisadero & 16361.0 & Control Site \\
\hline 15 & Mission St & Valencia & Precita & 16586.0 & Control Site \\
\hline 16 & Alemany & Ocean Ave & Ottawa Ave & 17333.0 & Bike Lane Site \\
\hline 17 & Alemany & Cotter St & Ocean Ave & 17333.0 & Bike Lane Site \\
\hline 18 & Market & Polk St & 11th St & 18245.0 & Bike Lane Site \\
\hline 19 & Market & Van Ness & Page St & 18245.0 & Bike Lane Site \\
\hline 20 & Market & Rose St & Haight St & 18245.0 & Bike Lane Site \\
\hline 21 & Market & Sanchez St & Noe St & 18245.0 & Bike Lane Site \\
\hline 22 & California St & Maple St & Arguello Blvd & 18347.0 & Control Site \\
\hline 23 & Bay St & Van Ness & Hyde & 18504.0 & Control Site \\
\hline 24 & Mission St & 30th St & Randall St & 18688.0 & Control Site \\
\hline 25 & Cesar Chavez & Tennessee St & Minnesota St & 19046.0 & Bike Lane Site \\
\hline 26 & Alemany & Rosseau St & Cotter St & 20971.0 & Bike Lane Site \\
\hline 27 & $\begin{array}{l}\text { Monterey } \\
\text { Blvd }\end{array}$ & Congo St & Acadia St & 21232.0 & Control Site \\
\hline 28 & Brannan St & Harriet & 7th St & 21273.0 & Control Site \\
\hline
\end{tabular}




\begin{tabular}{|l|l|l|l|l|l}
\hline $\mathbf{2 9}$ & Brannan St & 4th St & 3rd St & 21273.0 & Control Site \\
\hline $\mathbf{3 0}$ & Bay Shore & Tunnel St & Blanken Ave & 21594.0 & Bike Lane Site \\
\hline $\mathbf{3 1}$ & Folsom & Russ St & Moss St & 21970.0 & Bike Lane Site \\
$\mathbf{3 2}$ & Divisadero St & Post St & Bush St & 21970.0 & Bike Lane Site \\
\hline $\mathbf{3 3}$ & Gough St & Post St & Sutter St & 24179.0 & Control Site \\
\hline $\mathbf{3 4}$ & San Jose & 30th St & 28th St & 24971.0 & Control Site \\
\hline $\mathbf{3 5}$ & Guerrero & Cesar Chavez & 28th St & 26224.0 & Bike Lane Site \\
\hline $\mathbf{3 6}$ & Lincoln & 30th St & 27th & 26905.0 & Bike Lane Site \\
\hline $\mathbf{3 7}$ & Divisadero St & Golden Gate Ave & Grove & 21591.0 & Control Site \\
\hline $\mathbf{3 8}$ & Divisadero St & Grove & Oak & 24179.0 & Control Site \\
\hline $\mathbf{3 9}$ & Divisadero St & Oak & Walker & 24179.0 & Control Site \\
\hline $\mathbf{4 0}$ & 1st St & Market & Folsom & 24179.0 & Control Site \\
\hline $\mathbf{4 1}$ & $3^{\text {rd }}$ & 16 & 19th & 20147 & Control Site \\
\hline $\mathbf{4 2}$ & $3^{\text {rd }}$ & Jerrold & Cargo & 22246 & Control Site \\
\hline $\mathbf{4 3}$ & Battery & Market & Sacramento & 23027 & Control Site \\
\hline $\mathbf{4 4}$ & $3^{\text {rd }}$ & Williams & Paul & 11919 & Control Site \\
\hline $\mathbf{4 5}$ & Divisadero St & Post St & Bush St & 22400 & Control Site \\
\hline & Source: SFMTA, 2014) & & & \\
\hline
\end{tabular}


Chapter 4: Results

Citywide analysis

The study was designed to examine the effects of bicycle modal split on the traffic fatalities in California cities. Using the statistical techniques described in chapter 3, data was analyzed through rolling averages and ANOVA tests.

Moving Average

A preliminary data analysis is shown in figure 10 for California cities by bike friendliness. The graph in Figure 11 shows a 10 year moving average of data that has been compiled between the years 1990 and 2010. Each year is an average of the previous 10 years of traffic fatality data. For instance, the value shown for 1999 is the average of traffic fatalities in the years 1990-1999. The data will have to be further subjected to statistical analysis, but even with a simple ten year moving average a trend in the data is emerging. While all cities in this study show a downward trend in fatalities bicycle cities in general show a higher downward trend in traffic fatalities then the California selected city average.

There are certain limitations to this graph. It shows aggregate data from different cities and presents them as one when different cities may or may not behave similarly. This graph also does not depict changes in bicycle modal split for individual cities over time as the splits move them from one category (low medium or high) to another from 1990 to 2010. 


\section{Road Fatality Rate for California Cities}

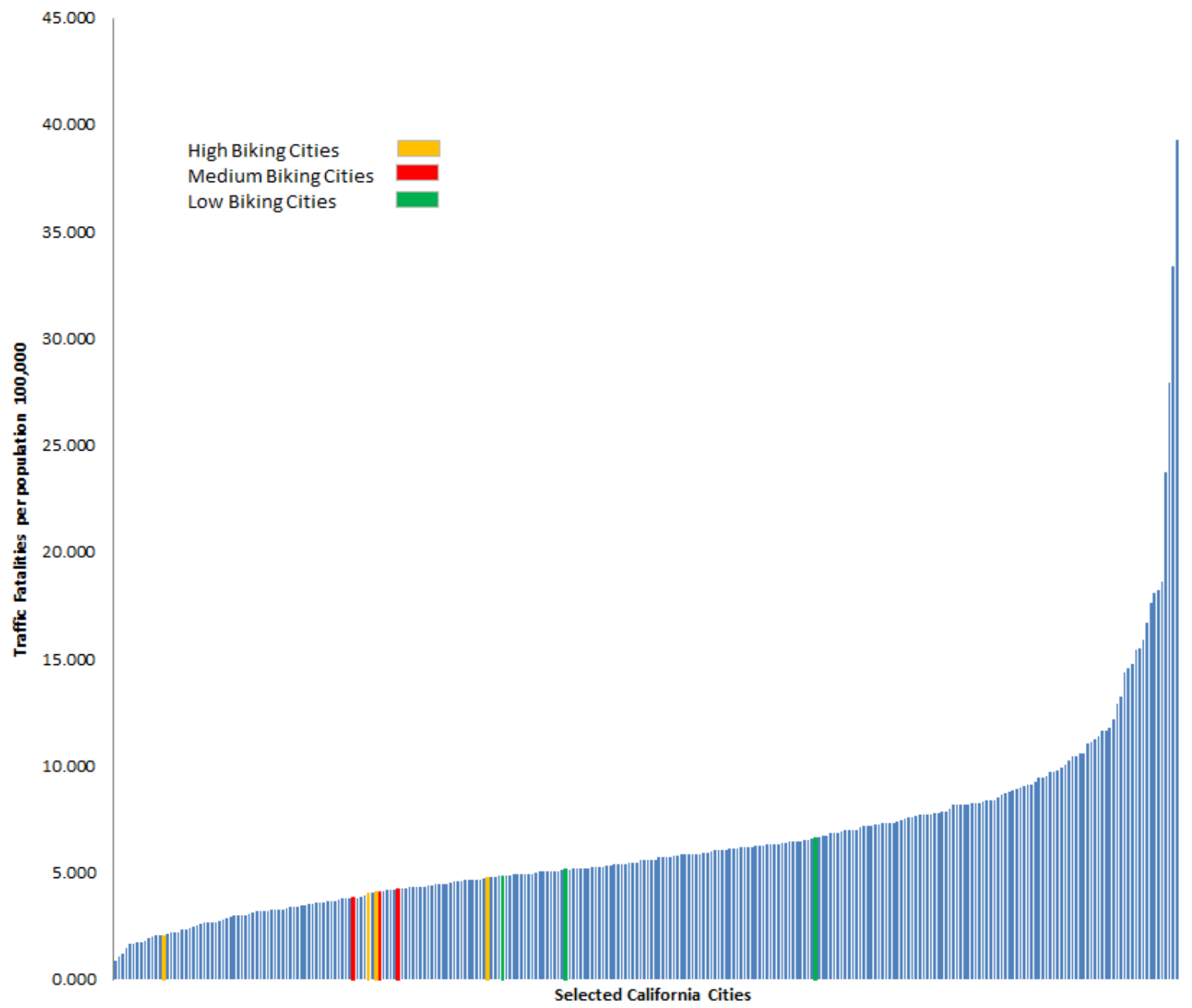

Source: Data compiled from California Highway Patrol, Statewide Integrated Traffic Records System (SWITRS), (1990-2010)

Figure 10: Traffic Fatality rate for selected California Cities 


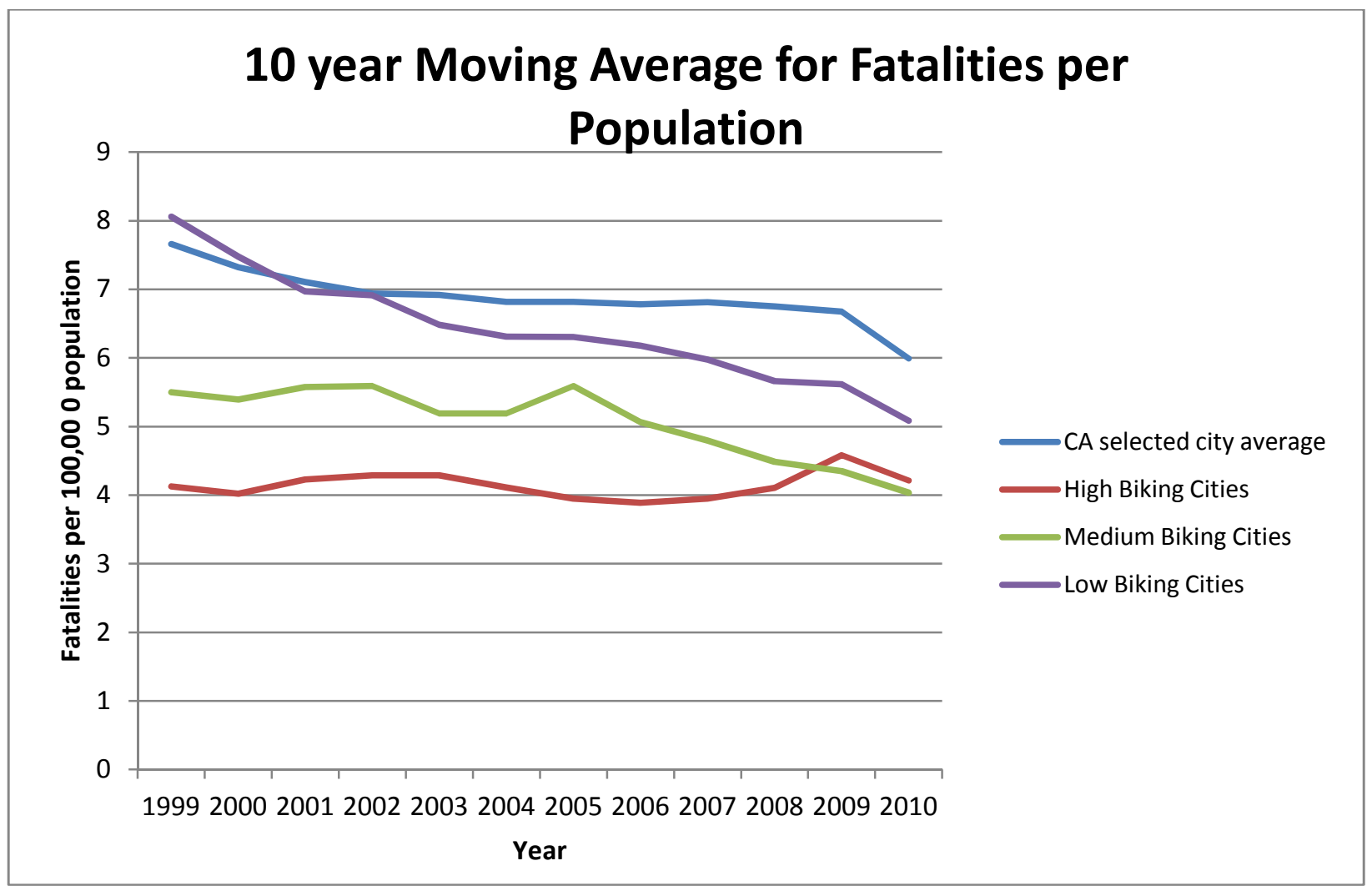

Source: Data Compiled from (SWITRS, 2010)

Figure 11: 10 year moving average for Selected California Cities 


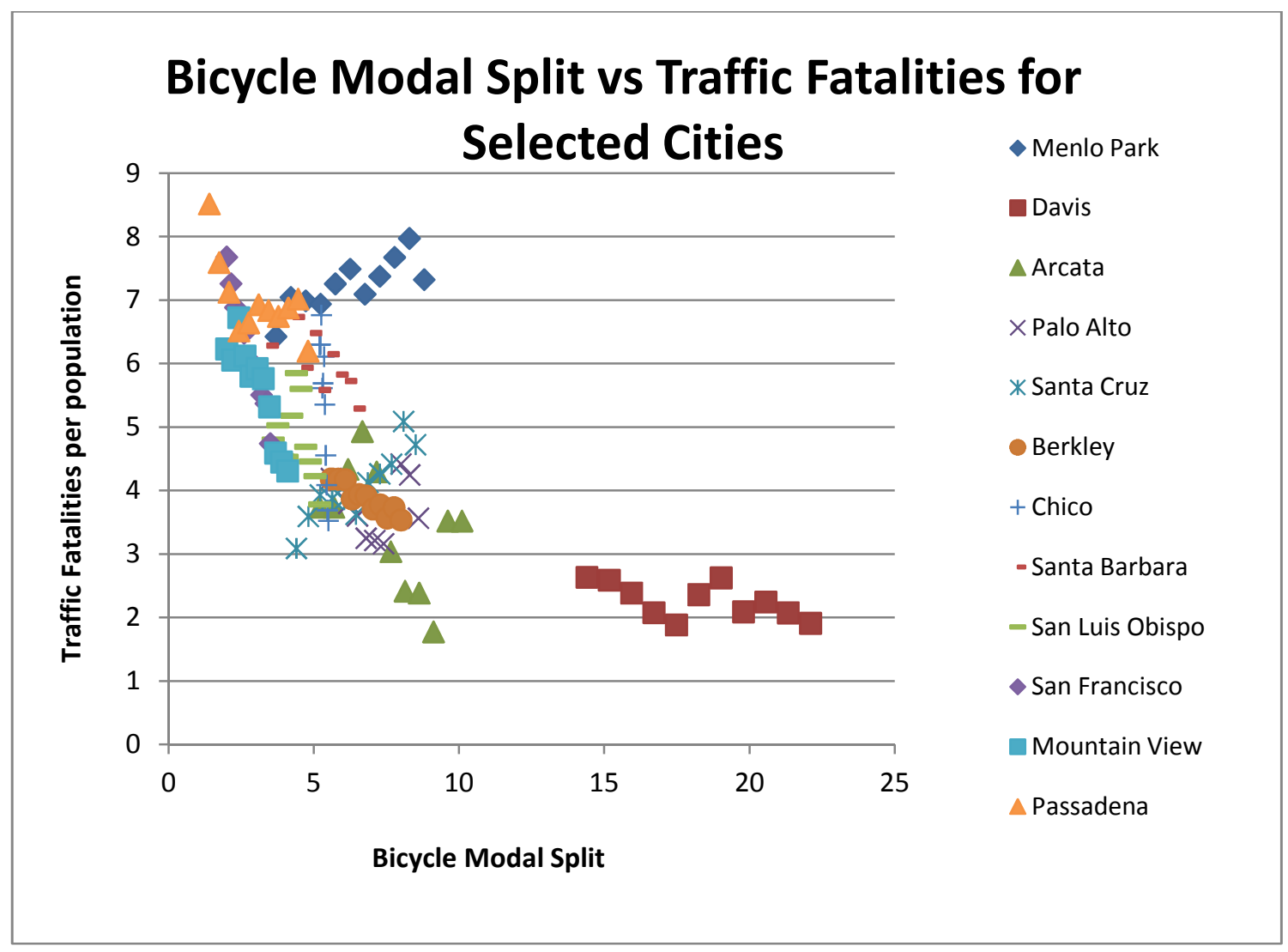

Source: Data compiled from the State Wide Integrated Traffic Records System (SWITRS, 2013) and Census Data (Census, 2010)

Figure 12: Bicycle Modal Split vs. Traffic Fatalities for Selected California Cities

The aggregate of traffic fatalities from 2000 to 2010 was then extracted in the form of 10-year moving averages for cities with high, medium and low bicycling and compared to the bicycle modal split in those cities for the associated years. Since census data was used to determine bicycle modal split, data was only available for the year 2000 and 2010, so the years in between were linearly extrapolated. The results of this comparison are shown in Figures 12. Results suggest that traffic fatality rates drop exponentially with increases in bicycle mode choice.

Curve estimation through Regression

Parameters were calculated using SPSS. The data was inputted so that the dependent variable was fatalities per 100,000 population per year and the independent variable was bicycle 
modal split. A variety of different regression analysis models were tested for the curve estimation, including a power function, a linear function, a logarithmic function, an inverse function, a quadratic function, a cubic function, an $\mathrm{S}$ function, a compound function, an exponential function and a growth function. The function with the $\mathrm{R}$ squared value that was closet to 1 was an exponential function as shown in equation 12 :

$$
F=a e^{E b} \quad \text { Equation } 12
$$

Where $\mathrm{F}$ is the traffic fatality per 100,000 population per year, $\mathrm{E}$ is the measure of bicycle modal split and $\mathrm{a}$ and $\mathrm{b}$ are parameters to be computed.

The data was inputted to SPSS to yield the coefficients in equation 12, the results shown below in equation 13:

$$
F=11.078 e^{E-.535} \quad \text { Equation } 13
$$

\section{A Note on Metrics Used}

The metrics for the city based analysis section of this study were chosen for a number of different criteria. The metric used for fatalities that was chosen was traffic fatalities per population. Another widely used metric is traffic fatalities per vehicle miles travelled (VMT). Both metrics are widely used and acceptable as traffic fatality rates. In the United States fatalities per VMT is used more often and in European studies fatalities per population is almost exclusively used. There isn't much discussion in other studies as to the merits of one metric over the other.

Another metric used in this study is percentage bicycle modal split. This is metric, as a means of measuring bicycle activity as a transportation use in a city, is by no means a perfect measurement. Some studies have pointed out that this metric frequently undercounts cyclists, 
since it doesn't count cycling to the store, students cycling to school and commuters cycling to a train station. While all those comments are valid, cycling in general is plagued with metrics that aren't as accurate or complete as the data that is gathered for cars, this is the best and perhaps only metric available that compares cycling in every city in California. There are different variant of this metric, such as cyclists commuters per square mile. While this metric isn't used often, but it is a way to compare cities to each other that account for the spatial differences of cities. Since some cities are more dense and compact then others this spatial element could be an important one to take into account. Figure 13 shows traffic fatalities per population vs. commuter cyclists per square mile. The results are similar to the previous results using the original metric, but don't follow as close of a relationship as the bicycle modal split metric. The reason why the relationship isn't as close might be because cities, like San Francisco, might have more bicycles per square mile they also have a lot more cars and buses per square mile, that inherently make the city less safe than it would be otherwise. More research would be needed to investigate which metric is the best to measure bicycle's influence on the transportation of a city as a whole. 


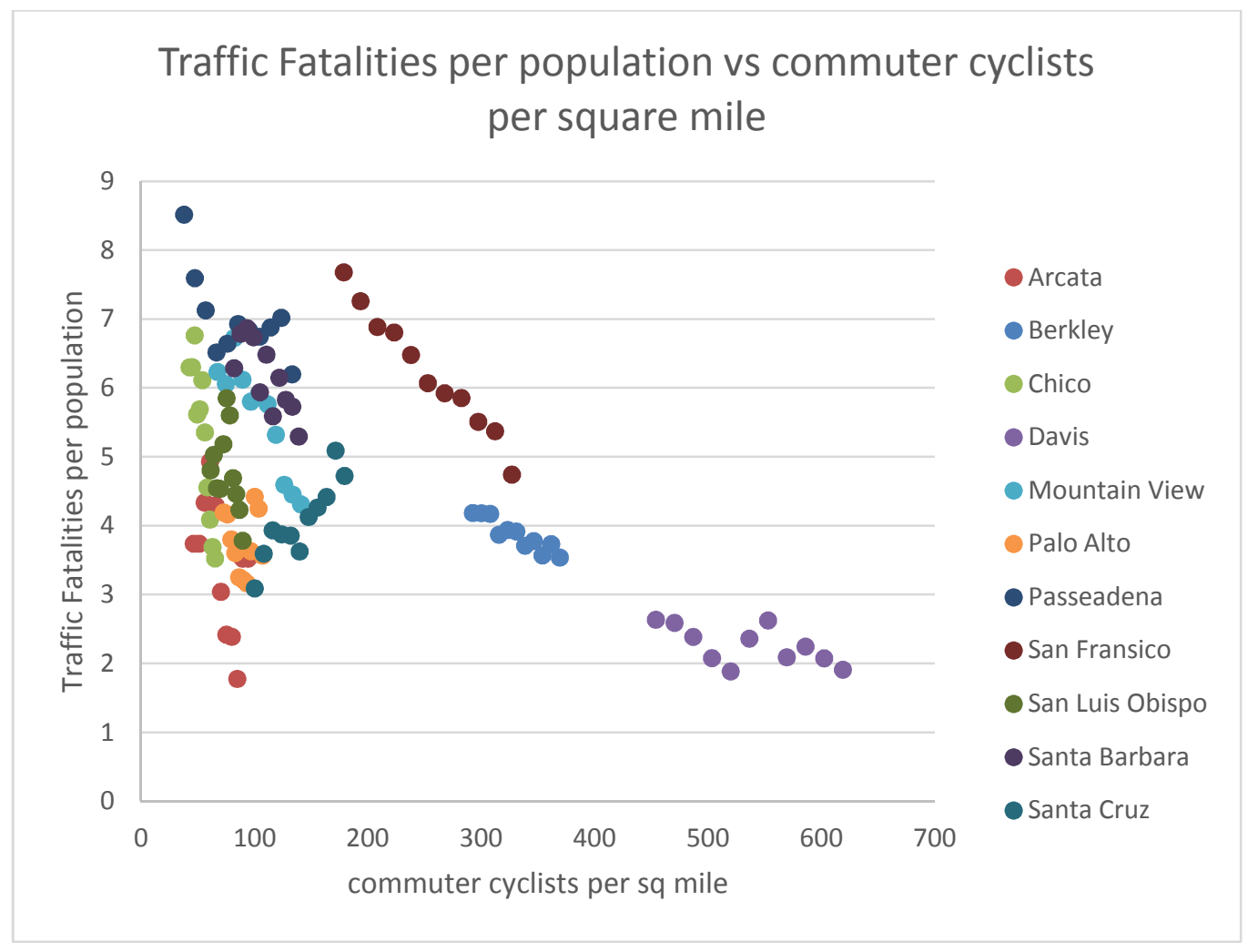

Figure 13: Traffic Fatalities per population vs commuter cyclists per square mile Exponential Regression

A number of different regression models were tested to see what equation would fit the data best. While the data also could fit a power function, an exponential function yielded the $\mathrm{r}$ squared values that was closes to 1 . This is a significant finding, in that other European studies on the safety effects of bicycles and pedestrians on traffic fatalities and injuries also follow an exponential function rather than a power function or any other type of equation (Elvik, 2009; Robinson, 2005)

Menlo Park: The Outlier

Figure 12 shows a very clear trend of a city's traffic fatalities decreasing with the increase in bicycle modal split with the exception of one city, Menlo Park. Menlo Park's traffic fatalities have actually increased in the past 20 years, a trend that is counter to the general 
California average. Exactly why Menlo Park isn't behaving as the other 11 cities is unclear in and would require further analysis. The best-fit regression model that was developed as part of this study didn't include Menlo Park and only contains the other 11 cities.

\section{Non-Linear Regression}

A best-fit regression model was developed for the dependent variable. The model includes two variables-the 10 year moving averages of traffic fatalities and the bicycle modal split. The R-squared is used in this study to compare the predictive power of different models. Among the number of different models tested, the one with the highest $\mathrm{R}$-square value was the exponential function. The R-squared for the exponential model is 0.738 meaning that about $74 \%$ of the variation in traffic fatalities can potentially be explained by the bicycle modal split. The model shows that as bicycle modal split increases, traffic fatalities decrease.

\section{Assumptions}

There are a number of assumptions throughout this study. One is that since bicycle modal split data is only available every 10 year, in this study 1990, 2000 and 2010, for all years in between it was assumed that biking modal split changed at a constant rate.

\section{Critical Mass}

One of the questions this thesis has sought to answer is what is the critical mass of cyclists needed in a city, when the amount of bikes in that city start to affect the traffic safety records of that city as a whole? There is not enough data to pin point an exact critical mass, hopefully with time California will have more cities that are bicycle friendly. It is likely that if there is a critical mass of cyclists such that their presence and associated infrastructure start to effect a city's traffic system as a whole in a measurable way that it is between $3 \%$ and $5 \%$, in the range that Mountain View and Pasadena are currently, but this is speculative without further 
study and data. Davis is past that point at $22 \%$ modal split in 2010 , where safety records are very low.

\section{Percentage Change}

Table 3 shows the percent change of fatality rate as a 10 year average between the years 2000 and 2010 as a rate of traffic fatalities per 100,000 population. Some general trends appear in Table 3 that are consistent through this thesis. The first is that high biking cities have a much lower traffic fatality rate than the California average, medium bike friendly cities and low biking friendly cities.

Table 3: Comparison of biking city's and California's average percent change of traffic fatality rate

\begin{tabular}{|l|l|l|r|r|r|}
\hline & $\begin{array}{l}2000 \\
\text { Fatality } \\
\text { Rate }\end{array}$ & $\begin{array}{l}2010 \\
\text { Fatality } \\
\text { Rate }\end{array}$ & $\begin{array}{l}\text { 2000 Bicycle } \\
\text { Modal Split }\end{array}$ & $\begin{array}{l}\text { 2010 Bicycle } \\
\text { Modal Split }\end{array}$ & $\begin{array}{l}\text { Percent } \\
\text { Change }\end{array}$ \\
\hline $\begin{array}{l}\text { California } \\
\text { Selected City } \\
\text { Average }\end{array}$ & 7.64188 & 5.989045 & $0.9 \%$ & $1.1 \%$ & $-21.63 \%$ \\
\hline Low Biking & 8.058199 & 5.084145 & $2 \%$ & $4 \%$ & $-36.91 \%$ \\
\hline $\begin{array}{l}\text { Medium } \\
\text { Biking }\end{array}$ & 5.500472 & 4.035974 & $4 \%$ & $6 \%$ & $-26.62 \%$ \\
\hline High Biking & 4.12432 & 4.209954 & $7 \%$ & $12 \%$ & $2.08 \%$ \\
\hline
\end{tabular}

Source: (Census,2010; SWITRS,2010)

While more data will be needed to reach more definitive conclusions, the data does seem to suggest that as a city gains more and more cyclist while there is an initial benefit from the gain either of cycling infrastructure or bicycle modal split, the effects tapper off over time. This can be seen when comparing the cities of Davis and Pasadena. The city of Davis, which does have above average traffic safety records, doesn't see any traffic safety improvements between the years 1999 and 2011. In 1999 Davis had a ten year average annual traffic fatality rate per 100,000 population of 2.47 while in 2011 it had a rate of 1.91 . While that still is a modest 
improvement in traffic safety records, it is well below the California average rate of improvement. In the same time period, in Davis there was an increase in cycling from a $14 \%$ modal split in 2000 , to a modal split of $22 \%$ in 2010 . Other high bike cities such as Palo Alto and Berkeley follow a similar trend. This is markedly different from cities like Pasadena. Pasadena has a decrease in traffic fatalities in 1999 to 2011 from a ten year average of 8.52 traffic fatalities per 100,000 population to a rate of 6.20 . A rate of decrease that is much higher than the California city's average. That happened as bicycle modal split rose from 1.4\% in 2000 to $4.8 \%$ in 2010 .

Study Limitations

This study has inherent limitations in its methodology. Traffic fatalities are depicted as a rate of fatalities per population. This gives some cities a built-in disadvantage. Cities that have more jobs within city limits than housing have a greater population during work hours than is recorded in the census. Cities that are adjacent to large universities also have a disadvantage because under many circumstances those students are not recorded among the population of the school location.

This study follows similar methods as Jacobsen's and to a lesser extent as Smeed's, both of which have been subjected to criticism, most notably by John Forester, who is a prominent, influential and respected member of the biking community. John Forester's main argument is that correlation doesn't demonstrate causation; he states that "All that Jacobsen has investigated are the accident rates in different areas or different times with differing amounts of bicycling. The most that he can show are correlations between the two sets of data, because he makes no investigation into any causal relationship." He also emphasizes that transportation is a 
complicated social system. The same criticisms he has on Smeed and Jacobsen can also be applied to this study.

This study is attempting to compare cities with varying spatial extent, density, and bicycle modal split. A future study, could analyze finer levels of geography, such as census tracts and parts of cities and look at the fatality rate on particular street segments.

\section{Future Study}

While this study attempted to be as comprehensive as possible, as California cities begin adding more bicycle infrastructure and modal split increases more cities can be analyzed to see if they follow a similar trend. 12 cities is not a lot of cities to make a generalized trend, perhaps future studies can be done on other cities in different states with high bicycle modal split.

Site based analysis

Percent Change

The percent change of crashes were calculated for both the selected bike lane sites and San Francisco total injury crashes and total fatal crashes, which are shown in Table 4. This was done as a comparison to see if the decrease in crashes on bike lane sites was indeed significant. The bike crashes did decrease over a ten-year period, but that trend is true for many cities in California and the United States as whole has seen traffic crashes generally decrease with time. So it was important for the purposes of this thesis to not only show that traffic crashes drop with bike lane installation but that they drop more significantly than the average. Table 4 shows this trend, that as a percent change, crashes dropped more at the selected sites than the City of San Francisco as a whole. 


\section{Table 4: Percent Change Comparison between Selected Sites and San Francisco Total}

\begin{tabular}{|l|l|l|l|l|l|l|l|l|l|}
2002 & 2003 & 2004 & 2005 & 2006 & 2007 & 2008 & 2009 & 2010 & 2011 \\
\hline
\end{tabular}

\section{Selected Sites}

\begin{tabular}{|c|c|c|c|c|c|c|c|c|c|c|c|}
\hline $\begin{array}{l}\text { Bike lane } \\
\text { Sites }\end{array}$ & 36 & 23 & 25 & 18 & 18 & 17 & 17 & 22 & 16 & 15 & $-22 \%$ \\
\hline $\begin{array}{l}\text { Control } \\
\text { Group }\end{array}$ & 17 & 14 & 20 & 19 & 18 & 24 & 15 & 13 & 13 & 26 & -- \\
\hline \multicolumn{12}{|c|}{ San Francisco as a whole } \\
\hline $\begin{array}{l}\text { Total } \\
\text { Fatal } \\
\text { Collisions }\end{array}$ & 39 & 46 & 37 & 32 & 39 & 51 & 35 & 39 & 29 & 33 & $-15 \%$ \\
\hline $\begin{array}{l}\text { Total } \\
\text { injury } \\
\text { collisions }\end{array}$ & 4,369 & 4,078 & 3,544 & 3,797 & 3,440 & 3,632 & 3,577 & 3,405 & 3,649 & 3,629 & $-17 \%$ \\
\hline Total & 4,408 & 4,124 & 3,581 & 3,829 & 3,479 & 3,683 & 3,612 & 3,444 & 3,678 & 3,662 & $-17 \%$ \\
\hline
\end{tabular}

\section{Source: (TIMS,2014) \& (SWITRS,2014)}

Empirical Bayes Method

The negative binomial models were fit using SPSS. SPSS calculated the level of significance for the variables: volume and segment length. Volume was not found to be significant with a p-value of 0.997 while segment length was found to be very significant with a P-value for 0.015. The goodness of fit is relatively good, with a Pearson Chi Squared value of 1.053.The closer the Pearson Chi Squared Value is to 1 then better the model.

SPSS yielded the equation to be: 


$$
y_{i}=e^{-1.392-0.002 x_{1}+0.425 x_{2}} \quad \text { equation } 14
$$

Where $\quad y_{i}=\#$ of collisions for the 5 year before period

$$
\begin{array}{cr}
x_{1}=\ln (\text { Volume }) & \text { in AADT } \\
x_{2}=\ln (\text { segment length }) & \text { in feet } \\
W_{i}=\frac{1}{1+k+y_{i}} & \text { equation } 15
\end{array}
$$

Where $\mathrm{k}=$ over dispersion parameter

$$
W_{i}=\text { weight for the road segment }
$$

SPSS calculated the over dispersion parameter for this data set to 0.567 . The higher the dispersion parameter, the more variability there is in the observed data. With a value slightly over 0.50 the model gave slightly more weight to the SPF, and slightly less to the observed data for this analysis.

The index of effectiveness $(\theta)$ was then calculated, which is a measurement of how effective the treatment was in reducing the collisions, by comparing the actual number of collisions with a prediction of future collisions using the data from how those streets have performed in the past. This calculation yielded the results in Table 5.

\begin{tabular}{l|l|l|l|} 
Table 5: Statistical Significant test Results \\
$\begin{array}{l}\text { Confidence } \\
\text { Interval }\end{array}$ & $\begin{array}{l}\text { Index of } \\
\text { Effectiveness }\end{array}$ & $\begin{array}{l}\text { Percent } \\
\text { Change in } \\
\text { Collisions }\end{array}$ \\
\hline 0.89476 & 0.68242 & 0.78859 & \\
\hline
\end{tabular}

If the index of effectiveness is less than 1 and the confidence interval doesn't contain 1 , then the results are statistically significant. The confidence interval is 0.682 to 0.894 and the index of effectiveness is 0.789 , as shown in table 12 , making the result of a $21 \%$ decrease in collisions to be statistically significant. 
Future Study

This study's site based analysis only focuses on the effect of class II bike lanes on traffic safety but an analysis could also be done on bike boulevards and separated bike lanes. This study only focuses on class II infrastructure because at least 30 sites were needed to have a statistically meaningful analysis and currently 30 bike boulevards do not exist in California and neither do 30 separated bike lanes that run along streets. In the future hopefully this will change, as many bike friendly cities have the addition of such infrastructure in their bike plans.

It should also be noted that this method only uses volume as part of the Empirical Bayes Method and does not use a more in depth analysis that takes into account type of road, including number of lanes and presence of two way left turn lane. There is also no adjustment factor for bike lanes in the Empirical Bayes Method in the highway safety manual, which is a limitation in the method. Also a more in depth and sophisticated statistical model could be used in this study, but more data collection would be needed. A future follow-up study could address these limitations. 
Chapter 5: Conclusion

This final chapter summarizes the findings from this study dissertation and proposes future work based on the ideas presented.

\section{Summary of Findings}

The objective of this thesis was to present an analysis of the effects of bicycles on traffic fatalities in terms of both bicycle modal split and bicycle infrastructure in the form of mainly class II bike lanes. The data used in this thesis includes a citywide analysis that contains yearly data from 11 cities in California and a site based analysis that includes data from 20 road segments in the city of San Francisco with bicycle lanes. This study was completed to better understand the impacts that cyclists have on the transportation system as a whole, specifically the citywide impacts of bicycles on the overall traffic safety for all modes.

\section{Citywide Analysis}

The results from the citywide analysis showed a relationship between bicycle modal split and traffic fatalities in selected California cities. Cities were chosen throughout the state of California such that their 2000 bicycle modal split was greater than 2\%. Using SPSS, a regression analysis was conducted to determine the mathematical relationship between fatal crashes and their bicycle modal split. The statistical analysis revealed the relationship to be exponential with an increase in bike modal split yielding large decreases in traffic fatalities, a decrease that is higher than the California average, when the bicycle modal split increased from about $2 \%$ to $4 \%$. When the bicycle modal split increase was from $4 \%$ to $6 \%$ the decrease in fatality rate for those cities was also larger than the California average decrease in traffic fatalities in the same time period but not as much as the cities whose biking increased from $2 \%$ 
to $4 \%$. When the bicycle modal split increased from an average of $7 \%$ to $12 \%$ there was little to no decrease in traffic fatalities.

Site Based Analysis

An Empirical Bayes analysis was done on selected sites in the City of San Francisco. These selected sites included 20 bike lane sites that had bicycle lane installed on them between the years 2005-2007. A control group of untreated sites that didn't have a bike lane on them between the years 2002 and 2012 were also selected for comparison. This group of 25 sites were chosen semi-randomly so that they were located in the general part of the city that the bike lane sites were, they were also chosen to have a similar length and traffic volume as the bike lane sites. The results from this analysis support the hypothesis that installing bike lanes in cities does indeed reduce the number of collisions by a statistically significant amount. At the selected sites, injury crashes reduced by $21 \%$ between the years 2002 and 2011 . 
References

1. Abdel-Aty and Radwan. (September 2000). Modeling traffic accident occurrence and involvement. Accid Anal Prev. ;32(5):633-42

2. Adams J. (1985). Smeed's law, seatbelts and the Emperor's new clothes. In: Evans L, Schwing RC, editors. Human Behavior and Traffic Safety. New York (NY): Plenum; 1985. p. 193-253.

3. Badger, Emily. (October 22, 2012). Dedicated Bike Lanes Can Cut Cycling Injuries in Half. The Atlantic. Retrieved from: http://www.theatlanticcities.com/commute/2012/10/dedicated-bike-lanes-can-cutcycling-injuries-half/3654/

4. Birk, Mia. (2010). Joy Ride: Pedaling Towards a Healthier Planet. Cadence Press

5. Bruni, Frank. (2011). Bicycle Visionary. New York Times. Retrieved from: http://www.nytimes.com/2011/09/11/opinion/sunday/bruni-janette-sadik-khan-bicycle$\underline{\text { visionary.html?pagewanted=all }}$

6. Burden, Dan. (2011). Dan Burden: Creating Livable Communities. [Video file]. Retrieved from https://www.youtube.com/watch?v=pNlTdoFV9bQ

7. Burton, Richard. (2008). Do cyclists have an exaggerated perception of the effectiveness of cycle helmets and the risks of cycling? Retrieved from http://www.onestreet.org/images/stories/pdf/048_Helmetperceptionpaper08England_001. pdf 
8. California Highway Patrol (CHP). (1990-2010). Annual Report of Fatal and Injury Motor Vehicle Traffic Collisions. CHP, Statewide Integrated Traffic Records System (SWITRS). Sacramento, CA. Retrieved from http://www.chp.ca.gov/switrs/.

9. CBC News. (2013, August 15). Stats Show Bike Lanes Make Streets Safer, City says. CBC News. Retrieved from http://www.cbc.ca/news/canada/thunder-bay/stats-show-bikelanes-make-streets-safer-city-says-1.1309955

10. Clark, D.E. and Cushing, B. M.. (2004). Rural and urban traffic fatalities, vehicle miles, and population density Accid Anal Prev. 2004 Nov; 36 (6): 967-72

11. Colville-Andreson, Mikael. (2012). Bike Culture by Design. [video file]. Retrieved from: http://www.tedxzurich.com/speaker/mikael-colville-andersen/

12. Elvik, Rune. (2009). The Non Linearity of Risk and the Promotion of Environmentally Sustainable Transport. Accident Analysis \& Prevention, Vol. 41, No. 4, 2009, p. 849-855

13. Evans, Leonard. (2004). Traffic Safety. Bloomfield Hills, Michigan: Science Serving Society.

14. Evans, Leonard. (1996). The Dominant Role of Driver Behavior in Traffic Safety. American Journal of Public Health, Vol. 86, pp 784-785

15. Garrard, J., Rose, G. and Lo, Sing Kai. (2007). Promoting transportation cycling for women: The role of bicycle infrastructure. Preventative Medicine. Retrieved from http://health-equity.pitt.edu/916/1/12pm.pdf

16. Geller, Roger. (April, 2011). Built it and They Will Come. Retrieved from: http://www.portlandoregon.gov/transportation/article/370893

17. Goldsmith, S., (1992). The national bicycling and walking study case study no. 1: reasons why bicycling and walking are not being used more extensively as travel modes. FHWA 
Publication No. FHWA-PD-93-041. US Government Printing Office, Washington, DC. Retrieved at http://www.bikewalktwincities.org/sites/default/files/NolandTraffic_Fatalities_and_Injuries.pdf

18. Harris, Teschke, Cripton, Winters, \& Reynolds. (2009). The Impact of Transportation Infrastructure on Bicycling Injuries and Crash: A Review of the Literature. Environmental Health 2009, 8:47. Retrieved from http://www.ehjournal.net/content/8/1/47

19. Hauer, E. (1997). Observational Before-After Studies in Road Safety. Pergamon Press, Elsevier Science Ltd., Oxford, England.

20. ITE/FHWA. (August, 2009). Traffic Calming: State of the Practice. Retrieved from: http://www.ite.org/traffic/tcstate.asp

21. Jacobsen, P.L. (2003). Safety in Numbers: More Walkers and Bicyclists, Safety Walking and Bicycling. Injury Prevention 9(3):205-209.

22. Lewis-Evans, Ben and Charlton, Samuel. (2006). Explicit and implicit processes in behavioural adaptation to road width, 610-617. In Accident Analysis and Prevention. Volume 38, Issue 3, Pages 610-617. Retrieved from: http://www.sciencedirect.com/science/article/pii/S0001457505002083

23. Mack, Arien and Rock, Irvin. (1998). Inattention Blindness An Overview. Cambridge, MA: MIT Press. Retrieved from: http://www.theassc.org/files/assc/2417.pdf

24. Mapes, J. (2009). Pedaling Revolution: How Cyclists Are Changing American Cities. Oregon State University, Corvallis. 
25. Marshall, W., and Garrick, N.. (2011). Evidence on Why Bike-Friendly Cities are Safer for all Road Users. Environmental Practice 13:16-27. Retrieved from http://files.meetup.com/1468133/Evidence\%20on\%20Why\%20Bike-Friendly.pdf

26. Marshall, W. and Gerrick, N.. (2011). Beyond Safety in Number: Why Bicycle Friendly Cities are Safer. Retrieved from http://www.planetizen.com/node/50020

27. Mok D, Gore G, Hagel B, Mok E, Magdalinos H, Pless IB, 2004. Risk compensation in children's activities: A pilot study. Paediatr Chile Health 2004;9(5):327-330

28. National Highway Traffic Safety Administration. (2010). Fatality Analysis Reporting System. Retrieved from http://www-fars.nhtsa.dot.gov/Main/index.aspx

29. New York City Department of Transportation. (2010). New York City Pedestrian Safety Study and Action Plan. Retrieved from http://www.nyc.gov/html/dot/downloads/pdf/nyc_ped_safety_study_action_plan.pdf

30. New York City Department of Traffic Management Division. (January 20,2011). Prospect Park West Bicycle Path and Traffic Calming Update [power point slides]. Presented to Community Board 6. Retrieved from: http://www.nyc.gov/html/dot/downloads/pdf/20110120_ppw.pdf

31. New York City Department of Transportation. (2012). New York City Bicycle Screen Counts. Retrieved from: http://www.nyc.gov/html/dot/downloads/pdf/2012-nyc-bicycle-screen-count.pdf

32. Persaud, B. (1990). Black Spot Identification and Treatment Evaluation. Ministry of Transportation, The Research and Development Branch, Ontario. 
33. Persaud, B., Retting, R., Lyon, C., (2004). Crash reduction following installation of centerline rumble strips on rural two-lane roads. Accident Analysis and Prevention $\underline{36}$, 1073-1079.

34. Raisman, Greg. (2009). Portland Bureau of Transportation. Retrieved from: http://www.portlandoregon.gov/transportation/article/267721

35. Reid Ewing, PhD, Richard A. Schieber, MD, MPH, and Charles V. Zegeer, MS (2003). Urban Sprawl as a Risk Factor in Motor Vehicle Occupant and Pedestrian Facilities. American Journal of Public Health, Vol. 93, No. 9. pp 1541-1545

36. Robinson, D. (2005). Safety in numbers in Australia: more walkers and bicyclists, safer walking and bicycling. Health Promotion Journal of Australia 16 (1): 47-51. Retrieved from http://www.cycle-helmets.com/hpja_2005_1_robinson.pdf

37. Sadik-Kahn, Janette. (2013). New York Streets, not so mean any more. [Video file]. Retrieved from: http://www.ted.com/talks/janette_sadik_khan_new_york_s_streets_not_so_mean_any_m ore

38. Simons. D. J., and Chabris, C.F. (1999). Gorillas in our mist: sustained inattentional blindness for dynamics events Perception 28(9) 1059 - 1074 retrieved from: www.cnbc.cmu.edu/ behrmann/dlpapers/Simons_Chabris.pdf

39. Smeed, RJ. (1949). Some statistical aspects of road safety research. J R Stat Soc A 1949:1-34.

40. Transport for London. (2008). Cycling in London. Retrieved from http://www.tfl.gov.uk/assets/downloads/businessandpartners/cycling-in-london-finaloctober-2008.pdf 
41. Todd K. Pedestrian regulations in the United States: a critical review. Transportation Quarterly 1992; 46: 541-59.

42. U.S. Census Bureau. (2010). Commuting Characteristics by Sex: 2010. Retrieved from http://factfinder2.census.gov/faces/tableservices/jsf/pages/productview.xhtml?pid=ACS 11_1YR_S0801\&prodType=table.

43. Vanderbilt, Tom. (2008). Traffic: Why We Drive the Way We Do. New York: Alfred A. Knopf.

44. World Health Organization. (2006-2007). Road Safety Estimated Road Traffic Death Rate (per 100,000 population). Retrieved from http://www.who.int/gho/road_safety/en/index.html

45. Yang, Y., \& Stieber, Z. (2011, December 29). Traffic Fatalities Reaching Record Low: Bike Lanes Part of the Solution. The Epoch Times. Retrieved from http://www.theepochtimes.com/n2/united-states/traffic-fatalities-reaching-record-low$\underline{166642 . h t m l}$

46. U.S. Department of Transportation and Federal Highway Administration. (2009) U.S. Department of Transportation and Federal Highway Administration, 2009. Retrieved from: http://www.bikesbelong.org/resources/stats-and-research/statistics/participationstatistics/\#sthash.gZBMhatJ.dpuf 
Appendix

SPSS Print Out

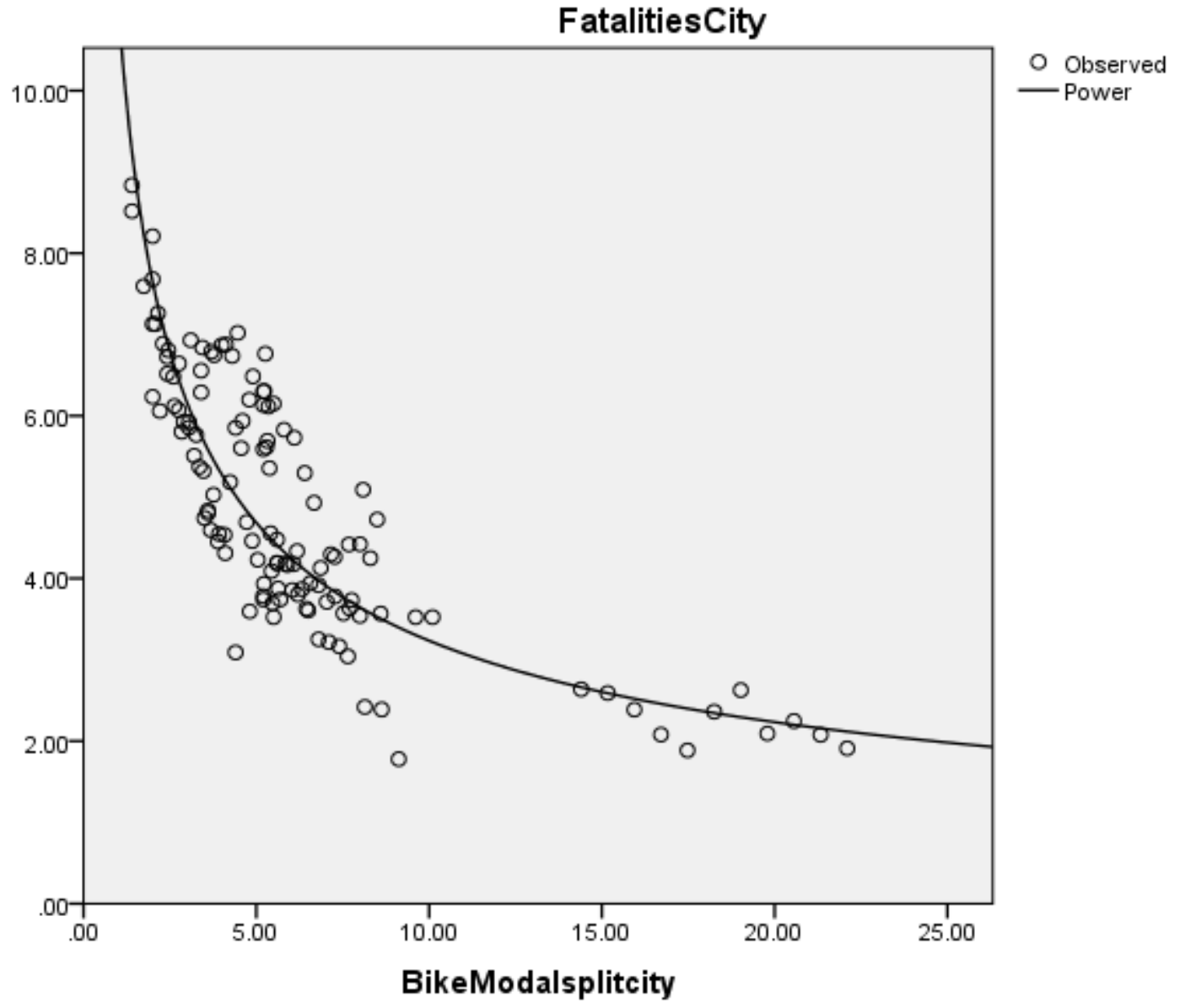

\begin{tabular}{|c|r|r|r|}
\hline \multicolumn{4}{|c|}{ Model Summary } \\
\hline R & R Square & $\begin{array}{c}\text { Adjusted R } \\
\text { Square }\end{array}$ & $\begin{array}{c}\text { Std. Error of } \\
\text { the Estimate }\end{array}$ \\
\hline .859 & .738 & .736 & .183 \\
\hline
\end{tabular}

\begin{tabular}{|c|c|c|c|c|c|}
\hline \multicolumn{7}{|c|}{ ANOVA } \\
\hline & $\begin{array}{l}\text { Sum of } \\
\text { Squares }\end{array}$ & Df & $\begin{array}{c}\text { Mean } \\
\text { Square }\end{array}$ & F & Sig. \\
\hline Regression & 11.858 & 1 & 11.858 & 355.213 & .000 \\
\hline
\end{tabular}




\begin{tabular}{|l|r|r|r|r|l|}
\hline Residual & 4.206 & 126 & .033 & & \\
\hline Total & 16.064 & 127 & & & \\
\hline
\end{tabular}

\begin{tabular}{|l|r|r|r|r|r|}
\hline & \multicolumn{7}{|c|}{ Coefficients } \\
& \multicolumn{2}{|c|}{$\begin{array}{c}\text { Unstandardized } \\
\text { Coefficients }\end{array}$} & $\begin{array}{c}\text { Standardized } \\
\text { Coefficients }\end{array}$ & $\mathrm{t}$ & Sig. \\
\cline { 2 - 6 } & $\mathrm{B}$ & Std. Error & Beta & \\
\hline $\ln$ (BikeModalsplitcity) & -.535 & .028 & -.859 & -18.847 & .000 \\
\hline (Constant) & 11.078 & .548 & & 20.216 & .000 \\
\hline The dependent variable is $\ln$ (FatalitiesCity).
\end{tabular}


Site Design SPSS Printout

Parameter Estimates

\begin{tabular}{|c|c|c|c|c|c|c|c|}
\hline \multirow[b]{2}{*}{ Parameter } & \multirow[b]{2}{*}{ B } & \multirow[b]{2}{*}{ Std. Error } & \multicolumn{2}{|c|}{$\begin{array}{c}\text { 95\% Wald Confidence } \\
\text { Interval }\end{array}$} & \multicolumn{3}{|c|}{ Hypothesis Test } \\
\hline & & & Lower & Upper & $\begin{array}{l}\text { Wald Chi- } \\
\text { Square }\end{array}$ & df & Sig. \\
\hline (Intercept) & -1.392 & 5.8294 & -12.817 & 10.034 & .057 & 1 & .811 \\
\hline LnAADT & -.002 & .5852 & -1.149 & 1.145 & .000 & 1 & .997 \\
\hline LnLength & .425 & .1783 & .076 & .775 & 5.688 & 1 & .017 \\
\hline (Scale) & $1^{\mathrm{a}}$ & & & & & & \\
\hline (Negative & 568 & 1760 & 309 & 1043 & & & \\
\hline binomial) & & & & & & & \\
\hline
\end{tabular}

Dependent Variable: Crash

Model: (Intercept), LnAADT, LnLength

a. Fixed at the displayed value.

Tests of Model Effects

\begin{tabular}{|c|c|c|c|}
\hline \multirow[b]{2}{*}{ Source } & \multicolumn{3}{|c|}{ Type III } \\
\hline & $\begin{array}{c}\text { Wald Chi- } \\
\text { Square }\end{array}$ & $\mathrm{df}$ & Sig. \\
\hline (Intercept & .057 & 1 & .811 \\
\hline LnAADT & .000 & 1 & .997 \\
\hline LnLength & 5.688 & 1 & .017 \\
\hline
\end{tabular}

Dependent Variable: Crash

Model: (Intercept), LnAADT, LnLength

\section{Omnibus Test ${ }^{\mathrm{a}}$}

\begin{tabular}{|c|c|c|}
\hline $\begin{array}{c}\text { Likelihood } \\
\text { Ratio Chi- } \\
\text { Square }\end{array}$ & df & Sig. \\
\hline 5.458 & & 2 \\
\hline
\end{tabular}

Dependent Variable: Crash

Model: (Intercept), LnAADT,

LnLength 
a. Compares the fitted model

against the intercept-only model.

\section{Goodness of Fit ${ }^{\mathrm{a}}$}

\begin{tabular}{|l|r|r|r|}
\hline & \multicolumn{1}{|c|}{ Value } & \multicolumn{1}{c|}{ df } & Value/df \\
\hline Deviance & 50.024 & 41 & 1.220 \\
Scaled Deviance & 50.024 & 41 & \\
Pearson Chi-Square & 43.160 & 41 & 1.053 \\
Scaled Pearson Chi- & 43.160 & 41 & \\
Square & -114.036 & & \\
Log Likelihood & & & \\
Akaike's Information & 236.072 & & \\
Criterion (AIC) & & & \\
Finite Sample & 237.072 & & \\
Corrected AIC (AICC) & & & \\
Bayesian Information & 243.299 & & \\
Criterion (BIC) & & & \\
Consistent AIC (CAIC) & 247.299 & & \\
\hline
\end{tabular}

Dependent Variable: Crash

Model: (Intercept), LnAADT, LnLength

a. Information criteria are in smaller-is-better form.

b. The full log likelihood function is displayed and used in computing information criteria.

\section{Continuous Variable Information}

\begin{tabular}{|ll|r|r|r|r|r|}
\hline & $\mathrm{N}$ & \multicolumn{1}{c|}{$\begin{array}{c}\text { Minimu } \\
\mathrm{m}\end{array}$} & \multicolumn{1}{c|}{$\begin{array}{c}\text { Maximu } \\
\mathrm{m}\end{array}$} & \multicolumn{1}{c|}{$\begin{array}{c}\text { Std. } \\
\text { Dean }\end{array}$} \\
\hline $\begin{array}{l}\text { Dependent } \\
\text { Variable } \\
\text { Covariate }\end{array}$ & Crash & 45 & .00 & 26.00 & 4.5333 & 4.74150 \\
& $\begin{array}{l}\text { LnAADT } \\
\text { LnLengt } \\
\mathrm{h}\end{array}$ & 45 & 9.21 & 10.20 & 9.7856 & .26941 \\
& 45 & 5.5 & 8.4 & 6.750 & .6829 \\
\hline
\end{tabular}

